\title{
Measuring and inferring the ice thickness distribution of four glaciers in the Tien Shan, Kyrgyzstan
}

\section{Article}

Cite this article: Van Tricht $L$ et al. (2021). Measuring and inferring the ice thickness distribution of four glaciers in the Tien Shan, Kyrgyzstan. Journal of Glaciology 67(262), 269-286. https://doi.org/10.1017/jog.2020.104

Received: 3 July 2020

Revised: 15 November 2020

Accepted: 16 November 2020

First published online: 22 December 2020

\section{Key words:}

Glacier mapping; glacier volume; ice thickness measurements; mountain glaciers; radio-echo sounding

\section{Author for correspondence:}

Lander Van Tricht,

E-mail: lander.van.tricht@vub.be (c) The Author(s), 2020. Published by Cambridge University Press. This is an Open Access article, distributed under the terms of the Creative Commons Attribution licence (http://creativecommons.org/licenses/by/4.0/), which permits unrestricted re-use, distribution, and reproduction in any medium, provided the original work is properly cited.

\author{
Lander Van Tricht ${ }^{1}$ (D), Philippe Huybrechts ${ }^{1}$ (D) , Jonas Van Breedam $^{1}$ (i), \\ Johannes J. Fürst ${ }^{2}$ (D), Oleg Rybak ${ }^{1,3,4}$, Rysbek Satylkanov ${ }^{5,6}$, \\ Bakyt Ermenbaiev ${ }^{5,6}$, Victor Popovnin ${ }^{7}$, Robbe Neyns ${ }^{1}$, Chloë Marie Paice ${ }^{1}$ \\ and Philipp Malz²
}

${ }^{1}$ Earth System Science and Department of Geography, Vrije Universiteit Brussel, Pleinlaan 2, 1050, Brussels, Belgium; ${ }^{2}$ Institute of Geography, University of Erlangen-Nuremberg, Wetterkreuz 15, D-91058, Erlangen, Germany; ${ }^{3}$ Water Problems Institute, Russian Academy of Sciences, Gubkina Str. 3, 119333 Moscow, Russia; ${ }^{4}$ FRC SSC RAS, Theatralnaya Str., 8-a, 354000 Sochi, Russia; ${ }^{5}$ Tien Shan High Mountain Research Center, National Academy of Science of the Kyrgyz Republic, Bishkek, Kyrgyzstan; ${ }^{6}$ Research Center for Ecology and Environment of Central Asia (Bishkek), Bishkek, Kyrgyzstan and ${ }^{7}$ Department of Geography, Lomonosov Moscow State University, 1 Leninskie Gory, 119991 Moscow, Russia

\section{Abstract}

Glaciers in the Tien Shan mountains contribute considerably to the fresh water used for irrigation, households and energy supply in the dry lowland areas of Kyrgyzstan and its neighbouring countries. To date, reconstructions of the current ice volume and ice thickness distribution remain scarce, and accurate data are largely lacking at the local scale. Here, we present a detailed ice thickness distribution of Ashu-Tor, Bordu, Golubin and Kara-Batkak glaciers derived from radio-echo sounding measurements and modelling. All the ice thickness measurements are used to calibrate three individual models to estimate the ice thickness in inaccessible areas. A cross-validation between modelled and measured ice thickness for a subset of the data is performed to attribute a weight to every model and to assemble a final composite ice thickness distribution for every glacier. Results reveal the thickest ice on Ashu-Tor glacier with values up to $201 \pm 12 \mathrm{~m}$. The ice thickness measurements and distributions are also compared with estimates composed without the use of in situ data. These estimates approach the total ice volume well, but local ice thicknesses vary substantially.

\section{Introduction}

Glaciers are shrinking on the global scale at an accelerated rate in response to increasing air surface temperatures (Zemp and others, 2019). Widespread consequences are the contribution of glaciers to global sea-level rise (Jacob and others, 2012; Zemp and others, 2019), the decline of glaciers as a source of water runoff used in the industry, households, agriculture and hydroelectrical power generation (Huss and Hock, 2018; Quincey and others, 2018; Schaefli and others, 2019), and the increased threat for downstream natural disaster events (Kääb and others, 2005; Kääb, 2011; Wang and Zhou, 2017). In this paper, we focus on the Tien Shan mountain range in Central Asia. Consistent with the global trend, an accelerated retreat of glaciers in the Tien Shan has been observed during the last several decades (Solomina and others, 2004; Hagg and others, 2013; Farinotti and others, 2015; Petrakov and others, 2016; Kraaijenbrink and others, 2017; Shahgedanova and others, 2020). In this region, glaciers are vital to the life of millions of people (Bolch, 2007; Immerzeel and others, 2010; Sorg and others, 2012; Pritchard, 2019). During dry summers, when water sources such as snow melt have been depleted and precipitation is absent, glacial meltwater provides a crucial source of fresh water used for drinking and irrigation (Immerzeel and others, 2010; Farinotti and others, 2015; Kraaijenbrink and others, 2017; Pritchard, 2019). As such, the Tien Shan is considered as the water tower of the dry lowland areas of the surrounding countries (Luo and others, 2018). Recent studies have demonstrated that at the end of this century, the water contribution of glaciers will be drastically reduced in this arid region (Immerzeel and Bierkens, 2012; Kraaijenbrink and others, 2017; Luo and others, 2018). Nevertheless, differences in the amount of glacier ice reduction and the sensitivity of individual glacier basins to climate change remain large.

To be able to make precise projections about future glacier volume and the evolution of glacier-fed runoff under global warming in the Tien Shan, accurate assessments of glacier ice thickness distributions are necessary. Because of the lack of direct measurements, multiple models have been developed and applied to derive the ice thickness distribution of a glacier from surface characteristics and the principles of ice flow dynamics (Huss and Farinotti, 2012; Linsbauer and others, 2012; Frey and others, 2014; Fürst and others, 2017; Ramsankaran and others, 2018; Maussion and others, 2019). These models have specifically been developed to be applied on regional (Fürst and others, 2018) to global scales 
(Farinotti and others, 2019). Although these models consider available thickness observations, point measurements are not necessarily reproduced and large deviations are present, especially at the local scale. Moreover, differences between the individual reconstruction models are unsatisfying as a result of the scarcity of in situ measurements used for calibrating these models (Sorg and others, 2012; Unger-Shayesteh and others, 2013; Kutuzov and others, 2018; Farinotti and others, 2019) and additional detailed ice thickness reconstructions based on measurements are needed. To date, the ice thickness of only a handful of glaciers in the Tien Shan is known from geophysical observations using a radio-echo sounding (RES) system, and most of them are located in the eastern areas of the Tien Shan (Hagg and others, 2013; Zhen and others, 2013; Petrakov and others, 2014; Wang and others, 2014; Nosenko and others, 2016; Pieczonka and others, 2018).

In the light of the existing limitations, we used RES to measure the ice thickness of Ashu-Tor, Bordu, Golubin and Kara-Batkak glaciers in the Kyrgyz Tien Shan, where few prior measurements of ice thickness exist. Here, we present all our in situ ice point thickness measurements ( 1000 points). We extend these measurements to the entire glaciers using three different approaches based on the assumption of a constant yield stress (model 1) and on the principle of mass conservation (models 2 and 3 ). The three models are calibrated against the RES measurements. A cross-validation between modelled and measured ice thickness is performed for a subset of the data to assess the performance and to compose a weighted average optimal ice thickness distribution for every glacier. The latter can be used to (i) more accurately assess the glaciers total ice thickness distribution and associated ice volume, (ii) apply glacier evolution studies on a detailed scale and (iii) constrain ice thickness models developed to be applied in data-scarce regions. Furthermore, we compare the measurements and the composed ice thickness distribution with different ice thickness estimates and with the consensus estimate (Farinotti and others, 2019), all constructed from models without the use of direct in situ field measurements. As part of our comparison, we explore how the use of these estimates could affect ice volume assessments and glacier evolution studies.

\section{Location, fieldwork and ice thickness measurements}

\subsection{Study area}

The four glaciers studied are located in the Kyrgyz part of the Tien Shan, which is a mountain range that stretches for over $3000 \mathrm{~km}$ from the east of Xinjiang, China, to the west of Tashkent in Uzbekistan (Fig. 1). The mountain range contains several reference glaciers with monitoring records dating back to the 1950s and 1960s (WGMS, 2019). At present, the glacier coverage is $\sim 15000 \mathrm{~km}^{2}$ with an estimated total ice volume of $\sim 1000 \mathrm{~km}^{3}$ (Aizen and others, 2007; Farinotti and others, 2015; Baojuan and others, 2017). The interaction between the atmospheric circulation associated with the Siberian high and the westerlies provides the mountain range with a more temperate climate in the western and northern part and a more continental climate in the central and eastern areas (Aizen and others, 1997).

The four glaciers are all medium-sized valley glaciers and characterized by (long-term) glaciological monitoring programs maintained by different research institutes and in the framework of multiple projects. The first glacier is Golubin glacier, a mediumsized glacier, located in the Ala-Archa basin in the Kyrgyz Ala-Too range in the northwestern part of Kyrgyzstan. Surface mass-balance $(\mathrm{SMB})$ measurements on this glacier were started by the Kyrgyz unit of the hydro-meteorological service of the USSR in 1958 and continued up to 1994 (Hagg and others, 2004). In 2010, SMB and length change measurements were reinitiated in the framework of the Capacity Building and Twinning for Climate Observing Systems (CATCOS) and Central Asian Water (CAWa) projects and they continue today (Kronenberg and others, 2016; Hoelzle and others, 2017; Barandun and others, 2018). The three other glaciers are located $\sim 500 \mathrm{~km}$ to the east and are situated south of the large Issyk-Kul lake in the Inner Tien Shan. While Bordu glacier is located in the Ak-Shyirak massif, Ashu-Tor and Kara-Batkak glaciers are located in the Terskey Ala-Too. Nevertheless, Ashu-Tor glacier is positioned on the southern slopes, which is in the same plateau system as Bordu glacier (Arabel). This plateau is characterized by an annual precipitation of $300-400 \mathrm{~mm}$ primarily falling in summer (May-September). This implies that these glaciers receive most of the accumulation when ablation takes place (Khromova and others, 2003; Kronenberg and others, 2016). SMB measurements on Ashu-Tor and Bordu glaciers were initiated in 2014 and continue today. Kara-Batkak glacier is located on the northern slope of the Terskey Ala-Too range with a slightly higher total precipitation (Satylkanov, 2018). This glacier is significantly smaller than the three other glaciers. SMB measurements on this glacier started in 1947 and continued up to 1998. The measurements on this glacier were reinitiated in 2013 by the Tien Shan High Mountain Scientific Research Center as part of the CHARIS Project (Contribution to High Asian Runoff from Ice and Snow/Ice and snow contribution to the flow of High Asia) (Satylkanov, 2018).

\subsection{Field campaigns and RES soundings}

In August 2016, 2017 and 2019, field campaigns were accomplished to measure the ice thickness of the selected glaciers with a Narod RES system. This system has been applied in a very large number of studies to measure the ice thickness of mountain glaciers thanks to its ease of operation and its lightweight (Narod and Clarke, 1994; Fountain and others, 2000; Pattyn and others, 2003; Zekollari and others, 2013; Lambrecht and others, 2014). The RES system works via a transmitter, which sends a radio wave that penetrates into the ice. A low frequency of $5 \mathrm{MHz}$ was preferred to ensure a sufficiently large penetration depth of the radar signal and to limit the amount of attenuation due to disturbances in the glacier ice during summer (e.g. water inclusions). Such a low frequency ensures a clearer signal but results generally in a larger uncertainty of the measurements (lower vertical resolution, see Section 2.3). High frequencies on the other hand are often associated with a larger amount of signal attenuation and scattering but contain a higher vertical resolution. We anticipate that future field campaigns in Kyrgyzstan in winter or in spring can, in the absence of meltwater, use higher frequency RES systems (e.g. 10 or $20 \mathrm{MHz}$ ) with a lower error range in the measured ice thickness. Furthermore, unreachable areas in summer are likely more accessible during winter expeditions when the small crevasses are fully snow covered and a sledge radar system can be used. In addition, measurements can also be performed with airborne or heliborne systems (Gärtner-Roer and others, 2014; Langhammer and others, 2019).

The transmitted wave by the radar is reflected back from the glacier bed towards the surface and recorded by the receiver at a distance $(d)$ from the transmitter. The time it takes for the wave $(t)$ to get back to the surface is converted into the local ice thickness $(H)$ using

$$
H=\frac{1}{2} \times\left[v_{\mathrm{ice}}^{2}\left(t+\frac{d}{v_{\text {air }}}\right)^{2}-d^{2}\right]^{1 / 2},
$$

with $v_{\text {ice }}$ being the velocity of the wave through ice $\left(1.68 \times 10^{8} \mathrm{~m} \mathrm{~s}^{-1}\right)$ while the velocity of the signal in air $\left(v_{\text {air }}\right)$ is set at $3.00 \times 10^{8} \mathrm{~m} \mathrm{~s}^{-1}$. 


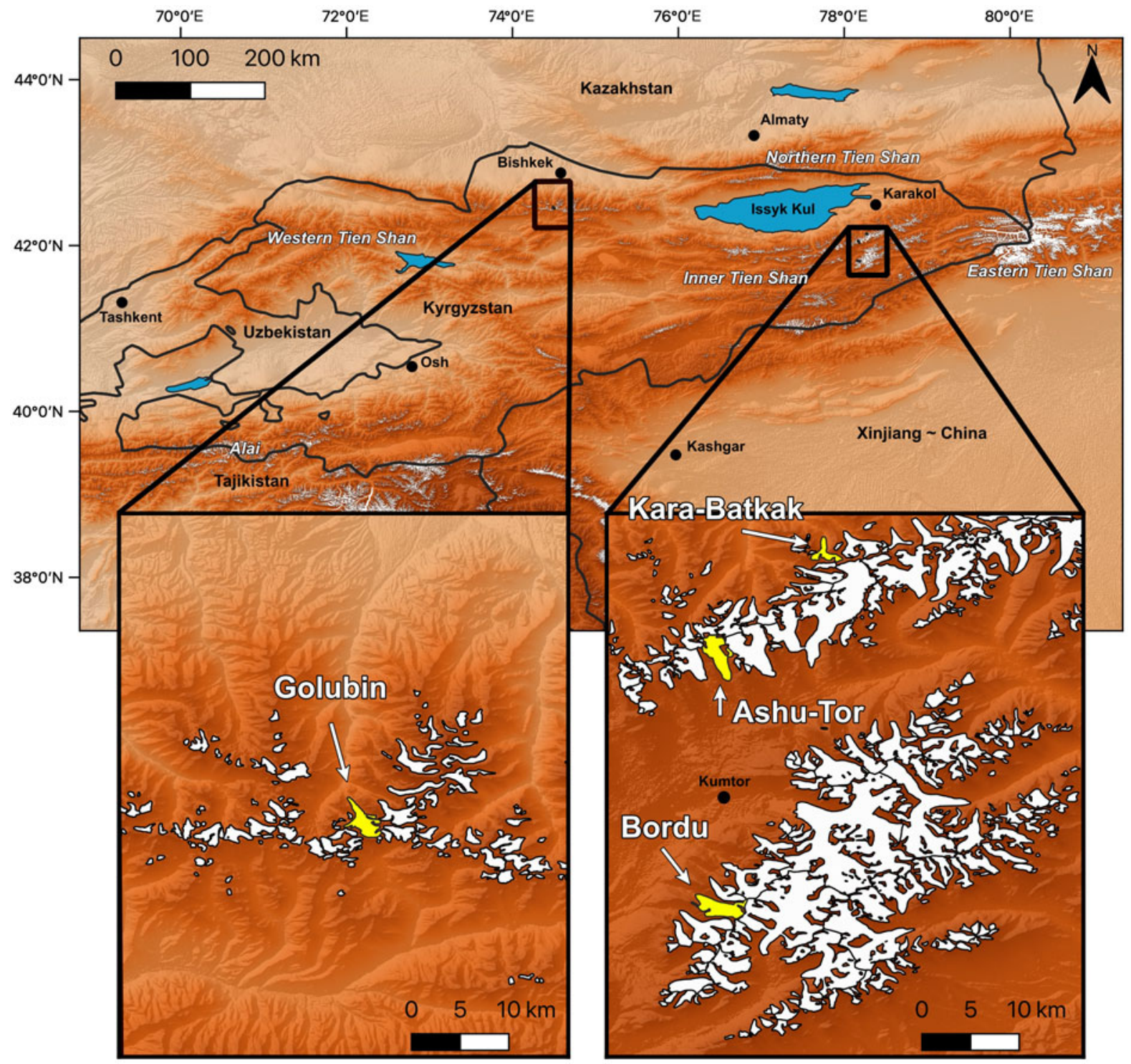

Fig. 1. Map of the Tien Shan mountain range in Kyrgyzstan. The selected glaciers are located in two different regions (Western Tien Shan and Inner Tien Shan). The glacier outlines are taken from the Randolph Glacier Inventory (RGI) version 6.0 (RGI, 2020). Background: Hillshade from SRTM.

GPS measurements of the exact locations of the transmitter and the receiver were made with a TRIMBLE GeoXH 3000, GeoXH 6000 and a GeoX7 and were differentially corrected afterwards (typical precision of $0.2 \mathrm{~m}$ ) using correction stations (Kumtor or Bishkek). The ice thickness was measured along one or two central flowlines and along multiple transverse profiles covering at least the entire ablation area and, where accessible, parts of the accumulation area (green points in Fig. 2 and Table 1).

The bed reflector was picked manually from the radargram by indicating the exact position of the reflected wave. Afterwards, the time interval between transmission and reception of the wave was determined and converted to the local ice thickness. In addition, a post-processing migration technique (Fig. 3) was implemented to filter out unrealistic measurements and replace them by more plausible solutions (Binder and others, 2009; Andreassen and others, 2015). In this way, the ice thickness was adjusted when the lowest point along an ellipse describing the possible reflection points was located inside the ellipse of the previous or next measurement along the profile. Evidently, it is impossible for the bedrock to be located at this depth because otherwise the neighbouring wave should have been reflected at the same point. These erroneous reflections are, for example, caused by large inconsistencies in the ice (rocks, water) and are removed to prevent an underestimation of the ice thickness (Lapazaran and others, 2016).

\subsection{Error of ice thickness measurements}

Concerning the estimation of the error associated with the thickness measurements, we follow the terminology in Lapazaran and others (2016). Since the location of the RES was measured using a differential GPS, and the GPR was stationary with a positional accuracy of $\sim 0.2 \mathrm{~m}$ in rather flat areas, we assume the horizontal error related to the exact positioning to be much lower than the error related to the ice thickness measurement itself $\left(\epsilon_{\mathrm{Hgpr}}\right)$. The latter depends primarily on the used radar wave velocity $(\mathrm{RWV}=c)$ and the timing of the reflected wave with $\tau$ - two-way travel time. This error can be written as:

$$
\epsilon_{\mathrm{HGPR}}=\frac{1}{2} \sqrt{\tau^{2} \times \epsilon_{\mathrm{c}}^{2}+c^{2} \times \epsilon_{\tau}^{2}}
$$

with $\left(\epsilon_{\tau}\right)$ being the timing error and $\left(\epsilon_{\mathrm{c}}\right)$ being the error related to the RWV. We used a constant RWV for all calculations, which 

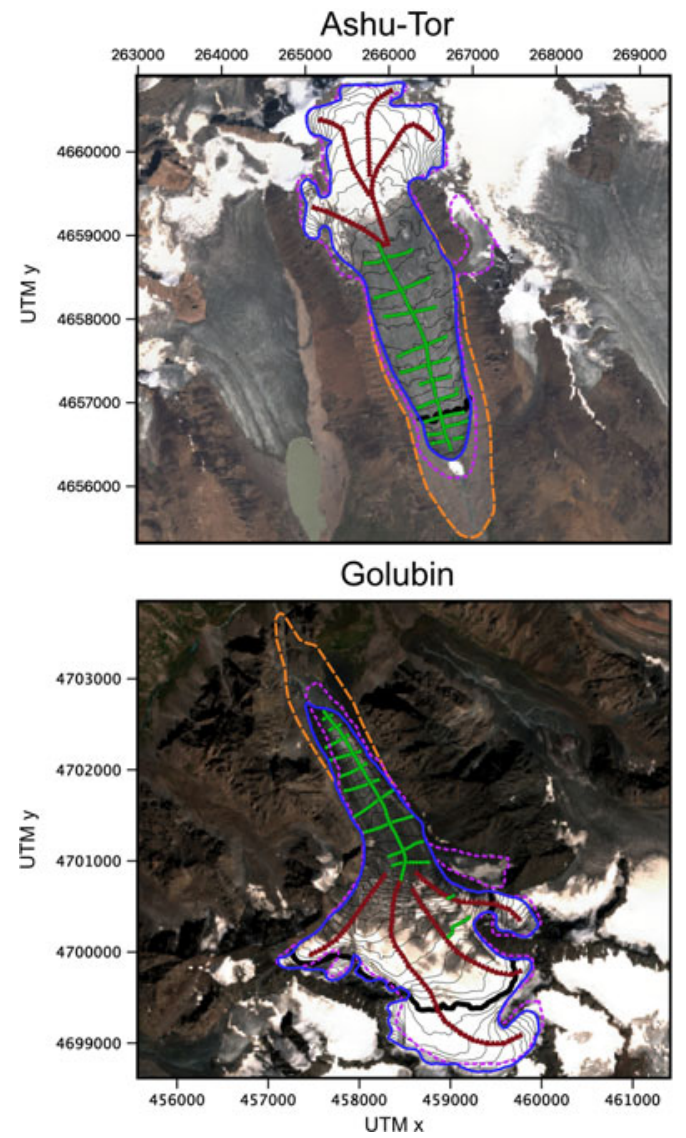
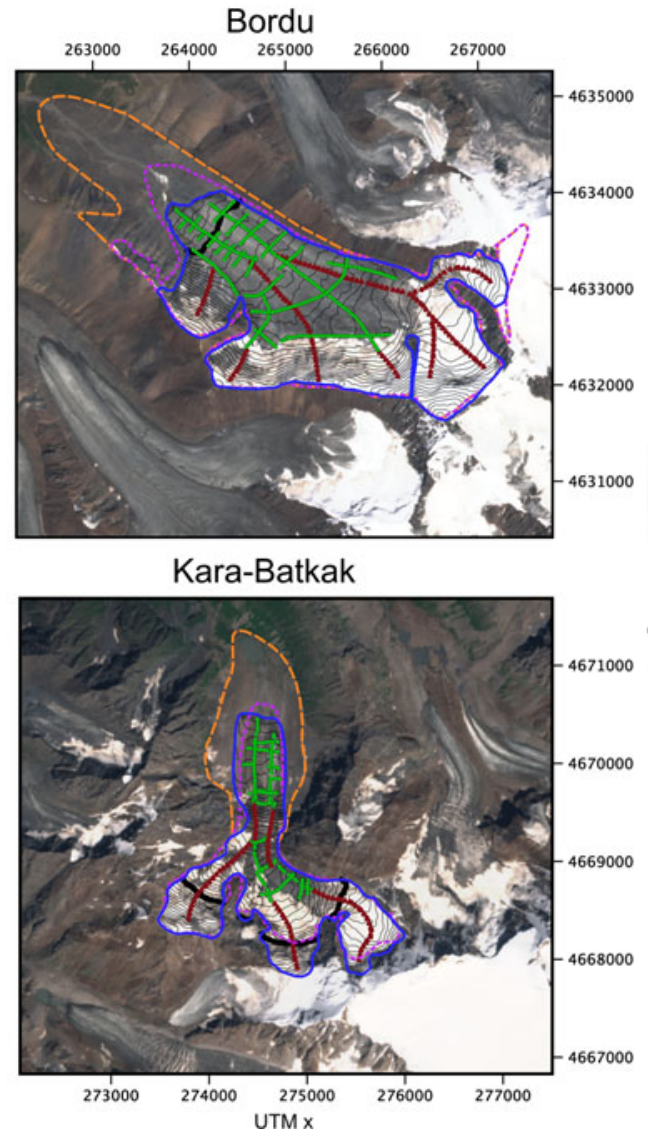

\section{0}

632000

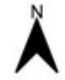

$0 \quad 5001000 \mathrm{~m}$ (2)

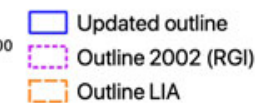

_. Outline LIA

Measurements

- Flowline points

$-4000 \mathrm{~m}$

Elevation contours

Fig. 2. Satellite image (Sentinel-2 true colour composite) of the different glaciers displaying the spatial distribution of the ice thickness points. The satellite images were acquired on 11/08/2019 for Ashu-Tor glacier, 27/07/2017 for Bordu glacier, 12/08/2019 for Golubin glacier and 27/07/2017 for Kara-Batkak glacier. The green points correspond to the GPR measurement locations. The red triangles correspond to the digitized additional points along the central flowlines in the unmeasured sections of the glaciers. The thin black lines are elevation contours from an adjusted DEM added for every $20 \mathrm{~m}$. The thick black lines correspond to the $4000 \mathrm{~m}$ elevation contour.

Table 1. RES collection and main characteristics of the glaciers

\begin{tabular}{lllll}
\hline & Ashu-tor & Bordu & Golubin & Kara-Batkak \\
\hline Year of campaign & 2019 & 2016 and 2017 & 2019 & 2016 and 2017 \\
Number of profiles & 11 & 22 & 13 & 21 \\
RES measurements & 284 & 376 & 213 & 206 \\
Area $\left(\mathrm{km}^{2}\right)$ & 4.76 & 4.89 & 4.64 & 2.27 \\
Altitude range (m) & $3873-4538$ & $3880-4725$ & $3343-4315$ & $3332-4373$ \\
Average slope (\%) & 20 & 35 & 35 & 52 \\
Orientation & SSE & NW & NNW & N \\
\hline
\end{tabular}

can be justified since we mainly performed measurements in the ablation areas that consist of clean ice and with an absence of firn and/or snow. The uncertainty introduced by this assumption is correlated with the ice thickness and the exact temperature of the ice. As the selected glaciers are likely polythermal glaciers, similarly to Sary-Tor glacier with warm ice at the base and cold ice on top of it (Petrakov and others, 2014; Nosenko and others, 2016), the error is expected to be of the order of $1-2 \%$ of the reconstructed ice thickness (Lapazaran and others, 2016; Lippl and others, 2019). The timing error $\left(\epsilon_{\tau}\right)$, a measure of how precisely the reflection can be determined in a RES record, is typically expressed as a function of the used frequency of the radar signal and is generally assumed to be constant for all measurements along a profile (Fountain and others, 2000). This error (often called the vertical resolution) is typically one-quarter of the wave-length of the used radar wave (Brandt and others, 2008; Mouginot and others, 2008; Fischer, 2009; Gärtner-Roer and others, 2014; Lambrecht and others, 2014), which in our case corresponds to $\sim 8 \mathrm{~m}$. The error associated with all the measurements appears thus to be almost completely determined by the error associated with the detection of the reflected wave and only limited by the assumption of constant RWV. We characterize the error of the measurements further in this research accordingly as $8 \mathrm{~m} \pm 2 \%$ of the measured ice thickness.

\subsection{Result of measured ice thicknesses}

After carefully analysing the different RES records, 981 point measurements could be used (Table 2 and Fig. 4). The RES records where the onset of the reflected wave could not be clearly recognized visually, due to a high level of distortion on the radar wave, were removed to prevent an incorrect ice thickness determination. We measured the thickest ice on Ashu-Tor with values up to $201.34 \pm 12.02 \mathrm{~m}$. This corresponds to the thickest ice that has been measured in the study area so far (Engel and others, 2012; Hagg and others, 2013; Petrakov and others, 2014, 2016). The maximum ice thickness (Table 2) was measured along the central flowline of Ashu-Tor glacier, close to the ELA where the slope is gentle.

The maximum measured ice thickness of the other glaciers appears to be significantly lower. The measurements revealed a maximum value of $147.90 \pm 10.96 \mathrm{~m}$ for Bordu glacier in the Ak-Shyirak mountain massif. The latter maximum is similar to the reported values of Sary-Tor glacier and glacier No. 354 in the neighbouring valleys (Hagg and others, 2013; Petrakov and others, 2014) and to the modelled ice thickness of Bordu glacier using the GlabTop model (Petrakov and others, 2016). 

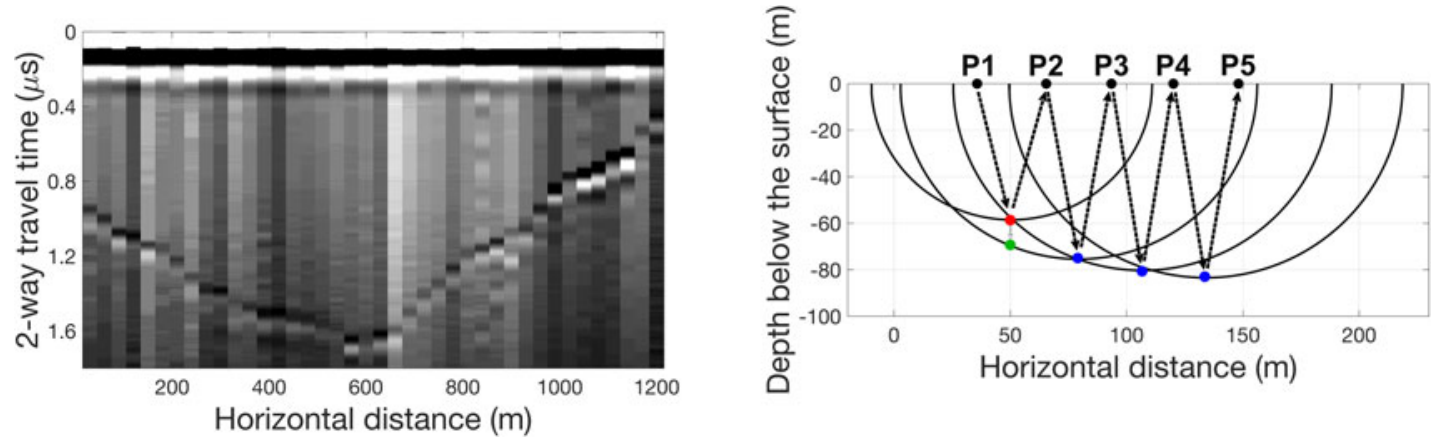

Fig. 3. Line intensity visualization of a transverse RES profile in the ablation area of Bordu glacier (left panel). Ellipses of four ice thickness measurements (right panel). The migration algorithm corrects the ice thickness from the first measurement since it lies inside the ellipse of the second measurement. The original ice thickness of the erroneous measurement is indicated by a red dot, the corrected thickness is indicated by a green dot, the original and correct ice thicknesses of the other measurements are indicated by a blue dot.

Table 2. Total number of measurements and maximum measured ice thickness of the different glaciers

\begin{tabular}{lllll}
\hline & Ashu-tor & Bordu & Golubin & Kara-Batkak \\
\hline Total number & 255 & 343 & 195 & 188 \\
Max ice thickness & $201.34 \pm$ & $147.90 \pm$ & $154.05 \pm$ & $113.91 \pm$ \\
(m) & 12.02 & 10.96 & 11.08 & 10.28 \\
\hline
\end{tabular}

Furthermore, the RES measurements of Golubin glacier have a maximum of $154.05 \pm 11.08 \mathrm{~m}$. This is in the same order as the maximum ice thickness measured on Adygene glacier $(\sim 140 \mathrm{~m})$, located in the neighbouring valley (Lavrentiev and others, 2014). However, the maximum ice thickness might be reached in the areas where no measurements were performed, in the gently sloping accumulation area. Lastly, the measurements on Kara-Batkak glacier indicated the thinnest ice with a maximum ice thickness of $113.9 \pm 10.28 \mathrm{~m}$. This rather thin ice is closely related to the steepness of Kara-Batkak glacier characterized by multiple ice falls at different elevations. This is in line with the plastic flow law that relates ice thickness directly to the surface slope (Zekollari and others, 2013).

\subsection{Glacier outlines and surface elevation}

The outlines of the four glaciers available in the RGI6.0 dataset of 2002 are updated to match the date of the outlines with the glacier margin at the date of the field campaigns. During the field campaigns, the frontal areas of the glaciers (except for Kara-Batkak glacier) were mapped using a DJI Phantom 4 Pro and a DJI Mavic to find the exact location of the glacier front and to produce a digital elevation model (DEM) of the glacier forefield (Fig. 5).

Plastic orange squares $(40 \times 40 \mathrm{~cm})$ and well-definable individual boulders were used as ground control points (GCP) to georeference the created Digital Surface Models (DSMs) by manually marking them in Pix4D. Following guidelines in the literature (Gindraux and others, 2017), we obtained a GCP density of at least $6 \mathrm{GCPs} \mathrm{km} \mathrm{km}^{-2}$ in the frontal areas. The glacier outlines are accordingly updated using optical satellite data from Sentinel-2 with a spatial resolution of $10 \mathrm{~m}$ for the main glacier area and using the drone imagery with a spatial resolution of $5 \mathrm{~cm}$ for the glacier front delineation. Concerning Kara-Batkak glacier, only satellite data are used. Especially for the debriscovered areas and the accumulation areas of the glaciers, specific attention is given to the adjustment of the outlines since the RGI6.0 outlines appeared to mismatch the glacier extent in these areas (dashed lines in Fig. 2). Here, the use of the RGI6.0 outlines would significantly underestimate the total glacier ice volume due to an underestimation of the total glacial area (Racoviteanu and others, 2009; Paul and others, 2013; Nagai and others, 2016). The TerraSAR-X add-on for Digital Elevation Measurement mission (TanDEM-X) (2013) is selected to represent the base representation of the glacier's surfaces. More recent DEMs such as the High Mountain Asia (HMA) DEMs (Shean and others, 2020) still contain artefacts spread over the glacier surfaces. Furthermore, the three models that are applied (Section 3) are mainly calibrated with locally averaged surface slope values that did not change significantly over the period of interest. The original TanDEM-X data are transformed into the projected coordinate system UTM44N (suitable between $78^{\circ} \mathrm{E}$ and $84^{\circ} \mathrm{E}$ ) for Ashu-Tor, Bordu and Kara-Batkak glaciers and UTM43N (suitable between $72^{\circ} \mathrm{E}$ and $78^{\circ} \mathrm{E}$ ) for Golubin glacier and interpolated to a regular grid of $25 \times 25 \mathrm{~m}$ using triangulation-based cubic interpolation. To correctly calculate the bedrock elevation from the ice thickness field, the elevations over the glacier area are adjusted for ice melt to match the date of the field campaigns. To do this, we first obtain average annual $\mathrm{d} h / \mathrm{d} t$ rates from the difference between the TanDEM-X DEM (2013) and the SRTM DEM (2000) over the entire glacier areas, see also Section 3.1.2. Then, we extrapolate the TanDEM-X DEM from 2013 to 2017 for Bordu and Kara-Batkak glaciers and to 2019 for Ashu-Tor and Bordu glaciers by subtracting the mean $\mathrm{d} h / \mathrm{d} t$ rates for the number of years until the year of the field campaigns. In the frontal areas (except for Kara-Batkak glacier), the surface DEM for the year of the field campaigns is derived from the photogrammetrically created DSMs from the UAV images (Fig. 5).

\section{Ice thickness modelling in unmeasured areas}

The spatial distribution of the ice thickness measurements shows that a substantial part of the glaciers was inaccessible during the field campaigns, especially in the accumulation areas (Fig. 2). Large crevasses, snow bridges, steep surfaces and changeable weather conditions inhibited access in these areas. Therefore, interpolation of the measured point ice thickness is required to obtain a glacier-wide ice thickness field. Direct interpolation between the measurements can be applied in the ablation areas but results in unrealistic extrapolation effects in the accumulation areas where in situ data are missing. Hence, we apply three different ice thickness models (c.f. yield stress model, mass flux flowline model, mass flux 2D model) to reconstruct the ice thickness over the entire glaciers on a regular grid of $25 \times 25 \mathrm{~m}$. The different input data of the three models are listed in Table 3. More details about the model's setup are given in the following sections. 

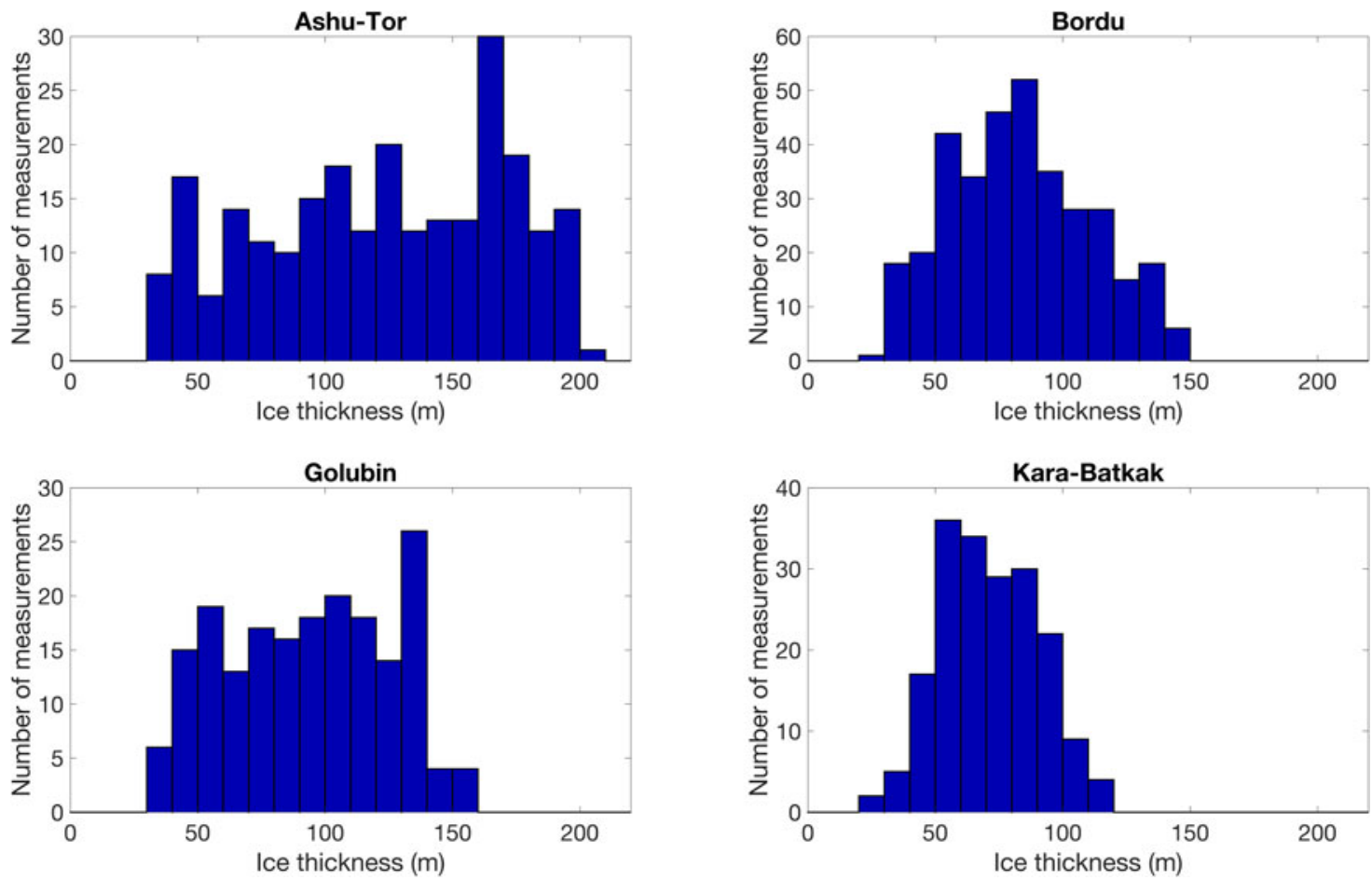

Fig. 4. Histogram of the RES ice thickness measurements performed on every glacier. The bin size is $10 \mathrm{~m}$.

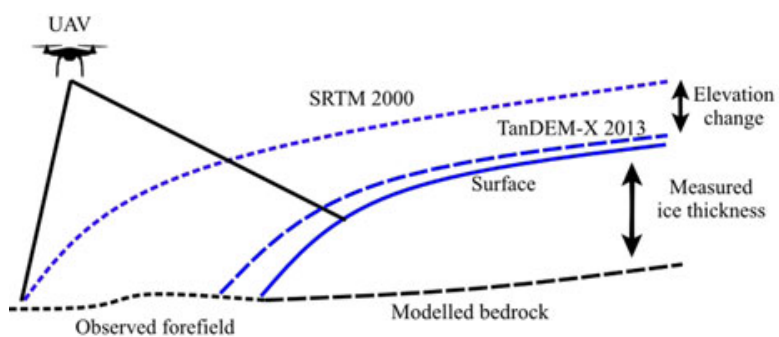

Fig. 5. The glacier front and forefield were mapped with a UAV to produce a DEM and to obtain an extension of the modelled bedrock field. The surface represents the surface elevation in the year of the field campaigns (2017/2019).

Table 3. Overview of the different input data required by the applied models

\begin{tabular}{|c|c|c|c|c|c|}
\hline Model & DEM & $\begin{array}{l}\text { Central } \\
\text { flowlines }\end{array}$ & Measurements & $\begin{array}{l}\text { SMB } \\
\text { gradient }\end{array}$ & $\mathrm{d} h / \mathrm{d} t$ \\
\hline Yield stress model & $\mathrm{x}$ & $\mathrm{x}$ & $x$ & & \\
\hline Mass flux flowline model & $x$ & $\mathrm{x}$ & $x$ & $x$ & $x$ \\
\hline Mass flux 2D model & $x$ & & $x$ & $x$ & $x$ \\
\hline
\end{tabular}

\subsection{Ice thickness modelling}

The first two models initially reconstruct the ice thickness at points along predefined glacier central flowlines (red points in Fig. 2). The ice thickness at these points is then interpolated between the flowlines and the margin to obtain a continuous gridded ice thickness field, using the ANUDEM algorithm developed by Hutchinson (1989). This algorithm has been designed to create a continuous surface mimicking the parabolic shape of a glacier bed from point measurements and has been applied in many studies (Fischer, 2009; Linsbauer and others, 2012). In the interpolation process, all the transverse ice thickness measurements are taken into account to optimize the quality of the entire ice thickness distribution. The ice thickness at the marginal gridpoints is set to $5 \mathrm{~m}$ representing the ice thickness at $\sim 12.5 \mathrm{~m}$ from the margin, as was done in Zekollari and others (2013). The uncertainty that is introduced by defining the location (and associated catchment area) of the flowlines and following interpolation using ANUDEM is absent for the mass flux 2D model, which immediately reconstructs the ice thickness over the entire catchment area (Fürst and others, 2017).

\subsubsection{Yield stress model}

The first model is based on the perfect-plasticity assumption and constant yield stress and builds on the models described in Linsbauer and others (2009, 2012); Li and others (2012) and Zekollari and others (2013). In this model, the basal shear stress along the central flowlines is set equal to an average yield stress $\left(\tau_{\mathrm{y}}\right)$ which is calibrated with the measured ice thicknesses based on the following relations:

$$
\begin{gathered}
\tau_{\mathrm{y}}=f \rho g H \sin \alpha, \\
\bar{\tau}_{\mathrm{y}}=\frac{\sum_{i}^{n} \tau_{\mathrm{y}}}{n},
\end{gathered}
$$

with $\alpha$ the local surface slope and $\rho$ the average ice density $\left(900 \mathrm{~kg} \mathrm{~m}^{-3}\right)$. Following $\mathrm{Li}$ and others (2012) and Pieczonka and others (2018), a shape factor $(f)$ is introduced to account for the drag by the valley walls. For simplicity, we assume a constant of 0.8 , similar to the value used for the consensus estimate (Farinotti and others, 2019) and in the parametrization scheme of Haeberli and Hoelzle (1995). This shape factor accordingly does not influence the ice thickness calculations (because it is kept constant) but produces more realistic basal shear stresses for a mountain glacier. We applied an averaging filter to prevent local topographical irregularities to dominate and minimize the spatial variability of the derived yield stresses. As such, we replaced the slope at a particular gridcell by the average slope of a window of $250 \times 250 \mathrm{~m}$ centred over the gridcell, following Binder and others (2009). Then, for all unmeasured point 
locations along the central flowlines situated within $200 \mathrm{~m}$ from a radar measurement, the yield stresses are determined by interpolating between the measured yield stress at the radar measurements and the calculated average yield stress $\left(\bar{\tau}_{\mathrm{y}}\right)$. For all other locations, the mean is ascribed directly. Afterwards, the local ice thickness is inferred from Eqn (5).

$$
H=\frac{\bar{\tau}_{\mathrm{y}}}{f \rho g \sin \alpha} .
$$

Previous studies showed that Eqn (5) tends to overestimate the ice thickness in very flat regions (small slope). Therefore, we implemented a minimum slope of 5\% (Farinotti and others, 2009, 2017; Carrivick and others, 2016; Pieczonka and others, 2018). However, we do not observe slopes smaller than $5 \%$ at the reconstruction points. In addition, as a test, we also derive the average yield stress for the four glaciers using the empirical equation of Haeberli and Hoelzle (1995), with $h_{\text {range }}$ being the difference between the maximum and the minimum elevation of the glacier (Eqn (6)).

$$
\tau_{\mathrm{y}}=0.005+1.598 \times h_{\text {range }}-0.435 \times h_{\text {range }}^{2} \text {. }
$$

This equation was determined on the examination of the bedrock of 62 formerly existing late-glacial ice bodies of ice in the European Alps and is often used in the literature to estimate the uniform yield stress of a particular glacier (e.g. GlabTop model) lacking in situ measurements (Linsbauer and others, 2009, 2012; Li and others, 2012). Table 4 shows that the calculated yield stresses of the four glaciers are typically of the order of 100$130 \mathrm{kPa}$. The rather large values are suggesting a cold structure of the glaciers. Kara-Batkak glacier is characterized by the largest average yield stress, which is associated with its range and its steepness (see Table 1). The value of $90.75 \mathrm{kPa}$ for Bordu glacier is somewhat lower than the average yield stress value of $100 \mathrm{kPa}$ found for glacier No. 354 (Hagg and others, 2013). This might be the result of the smaller amount of RES soundings in the central area on glacier No. 354. Table 4 also indicates that the std dev. of the calculated yield stresses $\left(\sigma_{\tau_{\mathrm{y}}}\right)$ is particularly large for Kara-Batkak and Bordu glacier (28\% of its mean value). Due to this variation, the assumption of a constant yield stress along the glacier flowlines does not seem to be valid for these glaciers. This is likely to result in a higher uncertainty of the derived ice thickness for the yield stress model. Nevertheless, Haeberli and Hoelzle (1995) found a similar spread of data points for shear stresses (30-45\%) reflecting the general variability of flow dynamics. For the other glaciers, but especially for Ashu-Tor glacier, the derived yield stresses fall into a narrower range (smaller $\sigma$ ).

Next to that, the empirically determined average yield stress is lower for three of the four glaciers, which implies that using this stress would lead to an underestimation of the ice thickness (Table 4). This is opposite to the study of Marshall and others (2011) who found that this value tends to overestimate the shear stress for small glaciers. Only for Bordu glacier, the use of this empirically determined stress would substantially overestimate the ice thickness. The deviation between the observationally and the empirically determined yield stresses might suggest that a different empirical relation holds for regions where the glaciers are polythermal, as is the case for other glaciers in the Tien Shan (Osmonov and others, 2013; Petrakov and others, 2014; Nosenko and others, 2016).

\subsubsection{Mass flux flowline model}

The second model is based on Farinotti and others (2009). This model has been used extensively to reconstruct the ice thickness of glaciers worldwide (Huss and Farinotti, 2012; Farinotti and
Table 4. Average yield stresses and the associated std dev. of the yield stresses of all measurements derived for the four glaciers (values in $\mathrm{kPa}$ )

\begin{tabular}{lrrrr}
\hline & Ashu-Tor & Bordu & Golubin & Kara-Batkak \\
\hline $\bar{\tau}_{\mathrm{y}}$ & 106.29 & 90.75 & 117.71 & 123.82 \\
$\sigma_{\tau_{\mathrm{y}}}$ & 15.01 & 25.01 & 25.63 & 34.32 \\
Empirical $\bar{\tau}_{\mathrm{y}}$ & 87.46 & 104.47 & 114.80 & 119.69 \\
\hline
\end{tabular}

The empirically derived yield stress for every glacier is based on the equation of Haeberli and Hoelzle (1995).

others, 2019) and for regional applications in, for example, Norway (Andreassen and others, 2015) and Austria (Helfricht and others, 2019). The principle is to combine knowledge of the SMB $(\dot{b})$ and surface elevation change rates $(\mathrm{d} h / \mathrm{d} t)$ to find the balancing flux divergence $\nabla . q$ via the conservation of mass equation and infer subsequently the ice thickness from this flux divergence:

$$
\nabla \cdot q=\dot{b}-\frac{\mathrm{d} h}{\mathrm{~d} t}
$$

First, the linear glacier-specific mass-balance gradients are calculated separately for the ablation and accumulation area from point stake and snow pit measurements. Concerning Ashu-Tor, Bordu and Kara-Batkak glaciers, SMB measurements are acquired via the framework of the CHARIS project (see Section 2.2) while for Golubin glacier, the data are obtained from the CATCOS and CAWa projects. Because the SMB measurements on Ashu-Tor glacier were only performed in the ablation area up to now (and for a limited number of stakes), we prefer to take the average of the gradients of Kara-Batkak and Bordu glaciers to represent the gradients of Ashu-Tor glacier, which is located in between. The different gradients and the estimated ELA are shown in Table 5. A small ablation gradient is obtained for Kara-Batkak and Bordu glaciers, in between values found in the past for Sary-Tor glacier (Ushnurtsev, 1991), Davydov (Aizen and Zakharov, 1989) and Batysh-Sook glacier (Kenzhebaev and others, 2017) and the average gradient of glacier No. 354 glacier (Kronenberg and others, 2016).

The rather small gradients are typical for glaciers located in areas with a continental climate characterized by limited annual precipitation. According to Dyurgerov and others (1994), a change towards larger SMB gradients might be caused by climate change in the area. The accumulation gradient of Bordu glacier appears to be very small, which corresponds to the low amount of precipitation in the Ak-Shyirak massif. For Kara-Batkak glacier, we derive an accumulation gradient of +2.05 m.w.e/ $1000 \mathrm{~m}$ up to $4150 \mathrm{~m}$ and $-2.82 \mathrm{~m} . \mathrm{w} . \mathrm{e} / 1000 \mathrm{~m}$ above this altitude. Such a negative gradient is often observed in the highest parts of glaciers as a result of a decreasing amount of precipitation, changing wind patterns or the steepness of the surface. Golubin glacier appears to have a steeper ablation gradient, close to $8 \mathrm{~m} . \mathrm{w} . \mathrm{e} / 1000 \mathrm{~m}$, which is associated with the higher annual precipitation in the western part of the Tien Shan $\left(\sim 700 \mathrm{~mm} \mathrm{a}^{-1}\right)$. We find an accumulation gradient of 2.06 m.w.e./ $1000 \mathrm{~m}$ for Golubin glacier up to $4150 \mathrm{~m}$ and $-1.17 \mathrm{~m}$.w.e./1000 $\mathrm{m}$ above $4150 \mathrm{~m}$. Subsequently, the apparent mass balance (AMB $\sim \tilde{b}$ in m.w.e) is calculated using the glacier-specific ablation/accumulation gradients and average surface elevation change rates $(\mathrm{d} h / \mathrm{d} t)$ over the entire glaciers (Eqn (8)). The latter are computed by smoothing average $\mathrm{d} h / \mathrm{d} t$ rates from the difference between the SRTM DEM (2000) and TanDEM-X (2013). TanDEM-X data and associated $\mathrm{d} h / \mathrm{d} t$ rates with respect to SRTM are processed following the workflow in Braun and others (2019), Farías-Barahona and others (2020) and Sommer and others (2020). As discussed in these studies, radar penetration of the C-band SRTM product is taken into 
Table 5. SMB gradients of the ablation and the accumulation area of the different glaciers (in m.w.e/1000 m) and the estimated altitude of the equilibrium line ( $\mathrm{m}$ )

\begin{tabular}{llll}
\hline & Ashu-Tor & Bordu & Kara-Batkak \\
\hline SMB gradient in the ablation area & 4.29 & 4.96 & 7.95 \\
Estimated altitude of the equilibrium line $(\mathrm{m})$ & 4250 & 4450 & 3850 \\
SMB gradient in the accumulation area & 1.51 & 0.94 & 2.06 up to 4150 \\
& & & -1.17 above 4150 \\
\hline
\end{tabular}

account by imposing a maximum $5 \mathrm{~m}$ penetration depth for the highest part of the glaciers, increasing linearly starting from $0 \mathrm{~m}$ at the $10 \%$ percentile of the glacier's elevation range. For the TanDEM-X DEM, surface penetration is assumed to be negligible compared to the general measurement accuracy. As such, errors on the $\mathrm{d} h / \mathrm{d} t$ product due to radar penetration can be expected to be very small.

$$
\tilde{b}=\frac{\dot{b}}{\rho}-\frac{\mathrm{d} h}{\mathrm{~d} t} .
$$

In the approach of Farinotti and others (2009), debris cover is taken into account by decreasing the AMB with $50 \%$ for cells covered with debris. However, for the selected glaciers, the extent of debris cover is limited (see Fig. 2) and we decided to not incorporate the debris. In the following step, the ELA is varied gradually (changing the local SMB) while keeping the $\mathrm{d} h / \mathrm{d} t$ fixed until the catchment (defined for every individual flowline) wide ice volume flux equals zero (Farinotti and others, 2009). The ice volume flux through every point along the central flowlines is then directly calculated by cumulating all the AMB values of the glacier catchment area upstream of the considered point contributing to the flow through the concerning point. Then, the ice volume flux is normalized by dividing the cumulative flux by the glacier effective width $\left(w_{c}\right)$ to obtain the mean specific ice volume flux for the cross-section of the glacier $\left(\bar{q}_{1}\right)$ (Eqn (9)) with $n$ being all the grid cells upstream of the considered point. The glacier effective width is manually derived for every point measurement along the central flowlines following Farinotti and others (2009).

$$
\bar{q}_{\mathrm{i}}=\frac{\sum_{n} \tilde{b}}{w_{\mathrm{c}}} .
$$

Finally, the ice thickness is inferred from the calculated mean specific ice volume flux using Glen's flow law and the Shallow Ice Approximation (SIA) with $\alpha$ being the slope averaged over an area of $250 \times 250 \mathrm{~m}$ (similar as for the yield stress model) with a flow parameter $(A)$ of $2.4 \times 10^{-15} \mathrm{kPa}^{-3} \mathrm{~s}^{-1}$ and $n=3$ the exponent in Glen's flow law:

$$
H=\sqrt[n+2]{\frac{\overline{q_{\mathrm{i}}}}{\sin ^{n}(\alpha)} \times \frac{(n+2)}{2 A(C \rho g)^{n}}} .
$$

$C$ is a correction factor, taking into account all uncertainties in the coefficients and is calibrated using the measured ice thicknesses. In contrast to Huss and Farinotti (2012), we do not introduce a specific factor applying for basal sliding since it is considered to be taken into account in the correction factor. We findvalues of $C$ between 0.13 (Ashu-Tor glacier) and 0.30 (Golubin glacier), which is lower than the values found for four glaciers in Switzerland (Farinotti and others, 2009). Similar to the yield stress model, we impose a minimum slope of $5^{\circ}$ to prevent an overestimation of the ice thickness in very gentle areas. Finally, the modelled thicknesses are ascribed to the unknown points of the flowlines.

\subsubsection{Mass flux 2D model}

Similar to the second model, the third approach to reconstruct glacier ice thickness is also based on the principle of mass conservation. Model 3 is informed by the central and transverse profiles to calibrate its parameters. The approach and its performance have been assessed for different glacier types on Svalbard (Fürst and others, 2017). It further participated in the ITMIX project (Farinotti and others, 2017), was applied on regional scales for the Svalbard archipelago (Fürst and others, 2018) and contributed to the consensus estimate for mapping the glacier thickness distribution worldwide (Farinotti and others, 2019). Unlike the first two models, this model directly computes the ice thickness distribution over the entire domain and not along predefined central flowlines. First, the AMB is derived from the linear mass-balance gradients presented in Table 5 and the surface elevation change rates between Tan-DEM-x and SRTM data. As no velocity information was available, the approach then infers the ice flux direction and magnitude. The flux is set to zero at the lateral margins (both parallel and perpendicular). During an iterative procedure, the AMB is adjusted to minimise a cost function that favours positive and smooth solutions and that penalises differences to the input AMB. This reduces undesired characteristics in the flux field resulting from inconsistencies in the input fields and anticipates a smoothed flux field (Fürst and others, 2017). To account for longitudinal coupling, a local and thicknessdependent smoothing is applied to the vector fields of the surface slope and the ice flux. In the mass flux 2D model, the flow parameter $(A)$ is computed based on the individual ice thickness measurements and extrapolated over the entire glacier domain. A mean value of $A$ is prescribed along the glacier margins to avoid unreliable extrapolation effects. In the last step, the glacier wide flux values are locally translated into thickness values assuming the SIA, similar to Eqn (10). For further details, the reader is referred to Fürst and others (2017).

\subsection{Model performance}

We quantify the performance of each model by comparing modelled and measured ice thicknesses. The models are calibrated with a randomly selected fraction of the total number of the ice thickness measurements. Subsequently, the modelled ice thicknesses are compared with the measured ice thicknesses for the withheld (not used for calibration) points. As metrics, the mean absolute error (MAE) and the standard error of the estimate (SEE) are used. The MAE is defined as the absolute difference between the modelled and the measured ice thickness while SEE takes into account the variance of the errors. Twenty performance experiments are performed for each model concerning five times $25,50,75$ and $90 \%$ of the measured ice thicknesses randomly withheld.

Clearly, the MAE and the SEE gradually increase when the percentage of withheld measurements is increased for all glaciers and all models (Fig. 6). However, overall, the MAE and SEE remain below $20 \%$, which is satisfactory for most purposes. This implies that the ice thickness models estimate the ice thickness at the location of the withheld measurements with an 

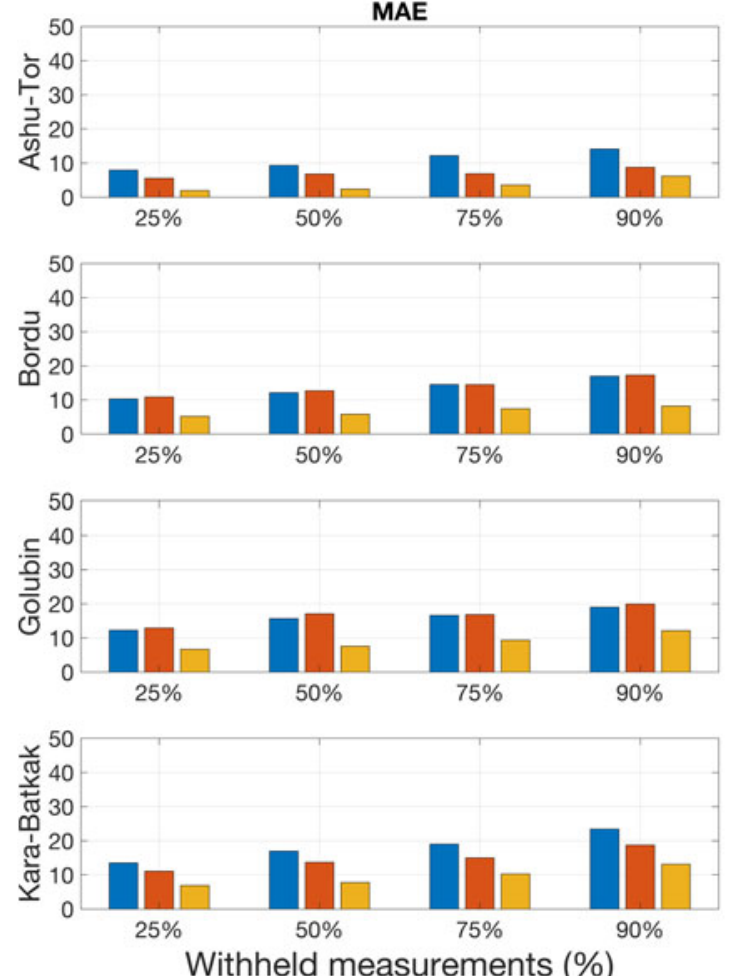
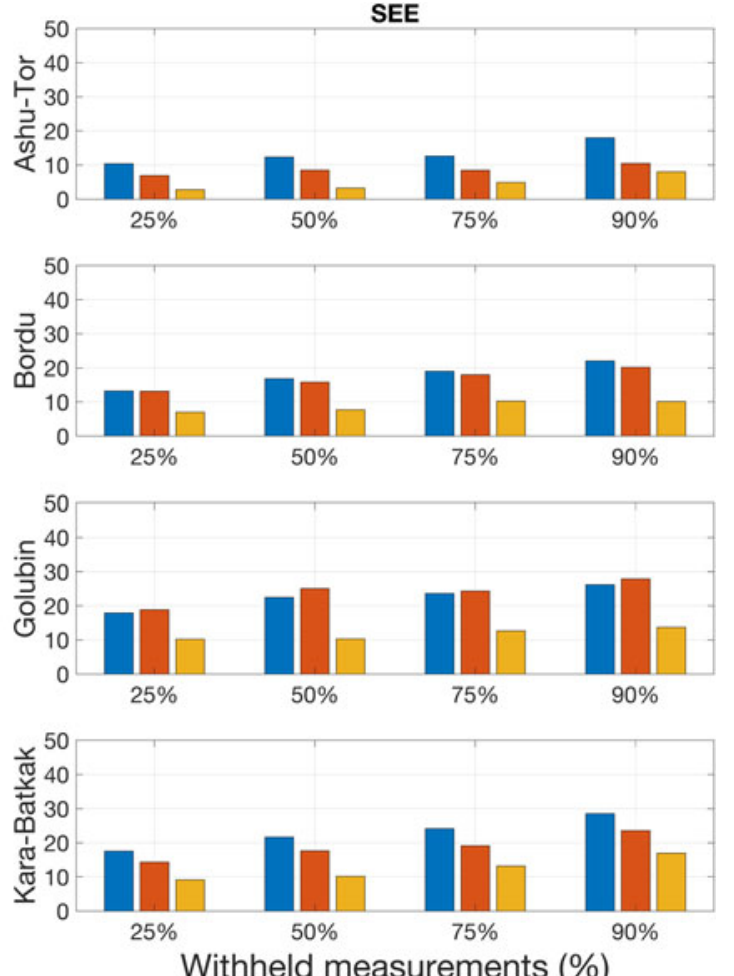

Withheld measurements (\%)

Fig. 6. Barplots of the mean absolute error (left) and standard error of the estimate (right) for the different percentages of withheld measurements. The units are in percentage. Blue $=$ yield stress model, red $=$ mass flux flowline model and yellow $=$ mass flux 2D model .

accuracy of $\pm 20 \%$. Concerning Kara-Batkak glacier, however, the MAE and SEE are larger, especially for the yield stress model. This is in line with the larger variability $(\sigma$ of $34 \mathrm{kPa})$ of the stresses calculated based on the measurements (Table 3 ). This suggests that this model assuming a constant yield stress is less appropriate to apply on Kara-Batkak glacier. This might reflect a larger variability of the flow dynamics (e.g. amount of basal sliding, ice deformation factor) (Linsbauer and others, 2012). For Bordu glacier, the difference between the performance of the yield stress model mass flux flowline model is smaller. All these findings suggest that the performance of glacier ice thickness models depends strongly on the glacier type and its characteristics. After all, Ashu-Tor glacier consists of a single glacier tongue while the shape of Kara-Batkak glacier is more complex and the glacier surface is significantly steeper. For all glaciers and all runs, the mass flux 2D model scores the lowest MAE and SEE. This demonstrates the overall best performance of this model for our dataset. Moreover, this hints for a more accurate ice thickness modelling when the mass flux is calculated in 2D instead of along central flowlines followed by an interpolation of the ice thickness using the ANUDEM algorithm (as is the case for the mass flux flowline model).

\subsection{Assembling composite ice thickness distribution}

Following Poisson's law of large numbers, an ensemble of different models is assumed to produce optimal results of ice thickness estimates since the average converges to the expected value. This was also observed by Farinotti and others (2017) in the ITMIX project. Based on the observations, up to five models were combined into a consensus estimate for the ice thickness of all glaciers on Earth (Farinotti and others, 2019). Following this procedure, we combine the three ice thickness distributions calibrated with all the measurements, created with the three models described in Section 3.2, into a composite ice thickness distribution for the selected glaciers. Based on the results discussed above, the mass flux 2D model performs better in areas with measurements. However, the mass flux 2D model might not perform better than the other approaches in areas where no thickness measurements were acquired. Similar to the approach in Farinotti and others (2019), a weight $\left(w_{\mathrm{j}}\right)$ is attributed to every model based on the mean absolute error (MAE) and the variance (SEE ${ }^{2}$ ) (Eqn (11)). The MAE and SEE corresponding to the version of the selection of $75 \%$ withheld points are used.

$$
w_{\mathrm{i}}=\mathrm{MAE}+\mathrm{SEE}^{2} .
$$

The final contribution (in percentage) of every model to the composite ice thickness field is shown in Table 6. Because of the significantly lower MAE and SEE of the mass flux 2D model, this model accounts for $\sim 60 \%$ of the composite ice thickness fields. The two other models are fairly equally weighted, except for Ashu-Tor and Kara-Batkak glaciers for which the yield stress model contributes substantially less.

Subsequently, the three ice thickness fields including all measurements are merged and the final ice thickness at every gridcell $\left(H_{\mathrm{i}}\right)$ is obtained using Eqn (12) with $h$ being the ice thickness at a particular gridcell and $H$ the composite ice thickness at the gridcell.

$$
H_{\mathrm{i}}=\frac{\sum h_{\mathrm{i}} \times w_{\mathrm{i}}^{-1}}{\sum w_{\mathrm{i}}^{-1}}
$$

\subsection{Ice thickness modelling error estimate}

At the location of the RES measurements, the error of the ice thickness distribution equals the error of the measurements themselves, which is $8 \mathrm{~m} \pm 2 \%$ of the measured ice thickness (see Section 2.3). Regarding the areas with a high density of RES 
Table 6. Contribution of the different models for every glacier

\begin{tabular}{llll}
\hline & $\begin{array}{l}\text { Yield stress } \\
\text { model }\end{array}$ & $\begin{array}{l}\text { Mass flux flowline } \\
\text { model }\end{array}$ & Mass flux 2D model \\
\hline Ashu-Tor & 11 & 23 & 66 \\
Bordu & 19 & 20 & 61 \\
Golubin & 19 & 18 & 63 \\
Kara-Batkak & 17 & 27 & 56 \\
\hline
\end{tabular}

measurements (especially the ablation areas), the error of the ice thickness estimates depends on the measurement's accuracy and the interpolation procedure. Because the density of RES measurements in these areas is high (glacier tongues), the MAE of the $50 \%$ withheld points is taken to represent the error. Figure 6 reveals a MAE of $\sim 10 \%$. In the areas without any RES measurements, the estimated ice thickness is accompanied by larger errors. Here, the potential errors are more difficult to estimate since the approach to compare modelled versus measured ice thicknesses cannot be applied. Therefore, we rely directly on the error characterization of the applied models and the MAE derived from the cross-validation test for the $90 \%$ withheld points. The latter corresponds to the largest error estimates with only $10 \%$ of the measurements used and corresponds to a very low density of ice thickness measurements for calibration. Combining all these values for the different glaciers would result in an average error of $10-15 \%$ for Ashu-Tor glacier, $15-20 \%$ for Bordu and Golubin glaciers and $20-25 \%$ for Kara-Batkak glacier. However, the mismatch calculated from this comparison likely underestimates the maximum local error in modelled ice thicknesses. It was found by Fürst and others (2017) that ice thicknesses are strongly spatially correlated implying that the MAE and SEE found in the cross-validation tests are probably too low to extend directly to the unmeasured areas. Therefore, it is suggested to take the mentioned upper bounds as the best indication for the error.

\section{Ice thickness distribution of Ashu-Tor, Bordu, Golubin and Kara-Batkak glaciers}

\subsection{Composite ice thickness distribution and glacier volumes}

The final composite ice thickness distributions are displayed in Figure 7. Ashu-Tor glacier is clearly characterized by the thickest ice in the central part of the glacier, along the glacier centreline, with thicknesses of up to $200 \mathrm{~m}$. The ELA is located in this rather flat area. Towards the glacier snout and towards the accumulation area, the ice thickness gradually declines. Furthermore, near the valley sides, the ice thickness decreases rapidly at similar rates on both valley sides (Fig. 7). The ice thickness of Ashu-Tor glacier is minimal at the highest parts of the accumulation area where the ice flux is limited, and the surface is steep (at the margin). Glacier volume (Table 7) is calculated to be $0.389 \pm 0.078 \mathrm{~km}^{3}$ taking into account the potential errors discussed in Section 3.4. For Bordu glacier, central parts show characteristic thickness values of $60-120 \mathrm{~m}$. This coincides with the large flat body of the glacier, which is in line with the plastic flow assumption relating ice thickness inversely to the surface slope (see Eqn (5)). Bordu glacier is characterized by generally steeper marginal zones in the accumulation areas (strong gradient in elevation contours), which results in minimum ice thickness in these parts. This matches closely to the modelled ice thickness distribution using the GlabTop model and surface elevations from SRTM and ASTER (Petrakov and others, 2016).

Cumulating the ice thicknesses over the entire glacier results in an ice volume of $0.291 \pm 0.058 \mathrm{~km}^{3}$ in 2017 . This is about twice as much as Sary-Tor glacier, which is located in the valley next to Bordu and which area is only slightly smaller (Petrakov and others, 2014). Golubin glacier on the other hand consists of two areas with thicker ice, separated by an icefall in the middle part of the glacier. At present, this icefall marks the boundary between the rather flat ablation area and the flat accumulation area. Two zones with an ice thickness of more than $120 \mathrm{~m}$ can be identified. One at the highest parts of the ablation area, just below the icefall. The other is located in the central part of the accumulation area where the gradient in elevation contours is weak. The pattern matches closely to the modelled ice thickness in Bolch (2015). However, the maximum ice thicknesses reported in the latter study are substantially larger, which is likely caused by the use of only a constant yield stress approach. The total ice volume of Golubin glacier appears to be $0.290 \pm 0.061 \mathrm{~km}^{3}$, which is similar to the volume of Bordu glacier. The larger error range of the ice volume of Golubin glacier is the result of the larger fraction of the unmeasured area of this glacier.

The calculated glacier ice volume of Golubin glacier is close to the ice volume value of $0.32 \pm 0.09 \mathrm{~km}^{3}$ estimated in Bolch (2015) using solely SRTM surface topography and a glacier outline corresponding to 2002 (RGI v6.0). The difference in volume can be explained by the ice volume loss between 2002 and 2019 and by the probable overestimation of the maximum ice thickness using the GlabTop model. Kara-Batkak glacier is clearly the smallest and thinnest glacier of the four with a more complex shape and different ice falls. Two areas with thicker ice $(>100 \mathrm{~m})$ are separated by a belt of thinner ice. Like for the other glaciers, the zones of maximum ice thickness are tied to the flat parts of the ice, both in the ablation as in the accumulation area. We obtain a total glacier ice volume of $0.096 \pm 0.019 \mathrm{~km}^{3}$ for Kara-Batkak glacier (Table 7).

\subsection{Bedrock topography and overdeepenings}

The bedrock topography of each glacier is obtained by subtracting the composite ice thickness distribution from the adjusted glacier's surface elevation (see section 2.5). The bedrock topography is extended to the glacier forefield by combining it with a DEM of the frontal area derived from drone imagery (Fig. 5). For Kara-Batkak glacier, where no UAV measurements were performed, the bedrock topography is linearly interpolated between the glacier snout in 2017 and the area outside the glacier margin in 2002 (RGI v6.0). In contrast to many (valley) glaciers, no significant overdeepenings (depressions in the bedrock) can be observed (Figs 8, 9). In general, the bedrock is (gradually) inclined towards the upper area of the glaciers.

Under the glacier snout, the bedrock slope is minimal, which might suggest a strong influence of glacier erosion and deposition as was also observed for glacier No. 354 (Hagg and others, 2013) and Sary-Tor glacier (Petrakov and others, 2014). Furthermore, the valley system of Ashu-Tor and Bordu glaciers looks very similar with a rather flat valley bottom and steeper areas at the valley margins. The bedrock of Golubin and Kara-Batkak glaciers on the contrary consists of more variable terrain with steeper sections (below the ice falls) and more flat sections just below and above the ice falls. Different smaller depressions in the bedrock for the upper areas of the valleys of Bordu and Golubin glaciers indicate a glacier cirque. These are valley heads shaped into hollows by the erosion of a (small) glacier. After glacier retreat, these can give rise to the formation of small lakes (tarn lakes). Such irregular bedrock topography can also be observed below glacier No. 354 in Hagg and others (2013).

\section{Comparison with ice thickness and volume estimates without in situ data}

It is impossible to measure the ice thickness of all glaciers with current surface-based methods. Therefore, methods and models 


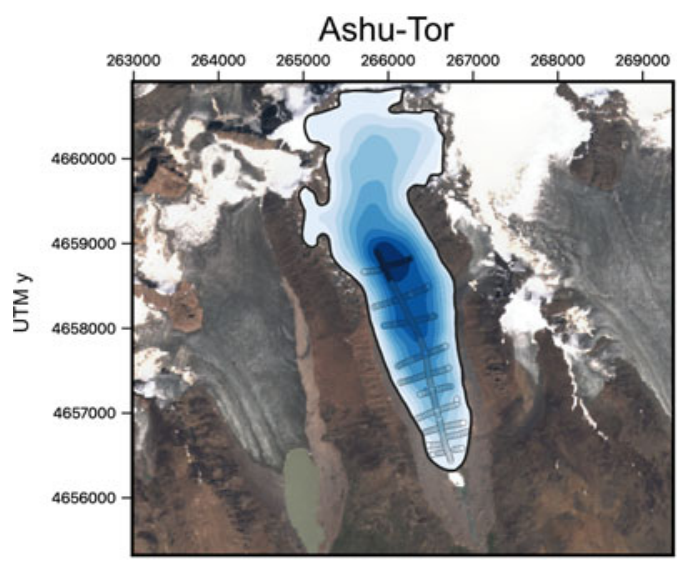

Golubin

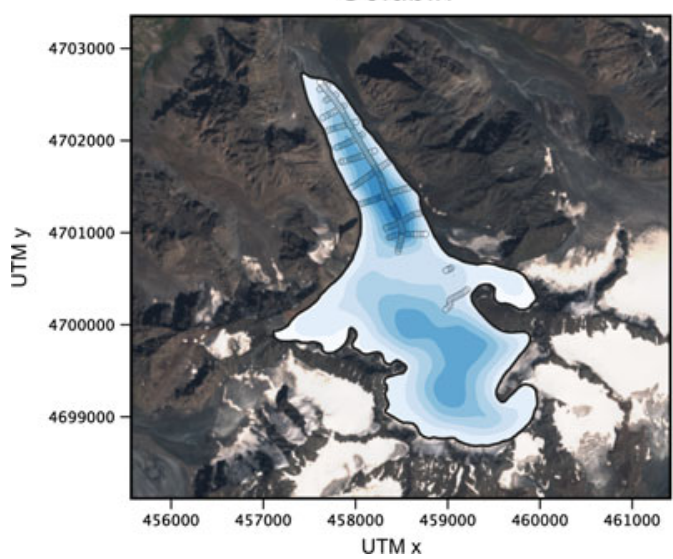

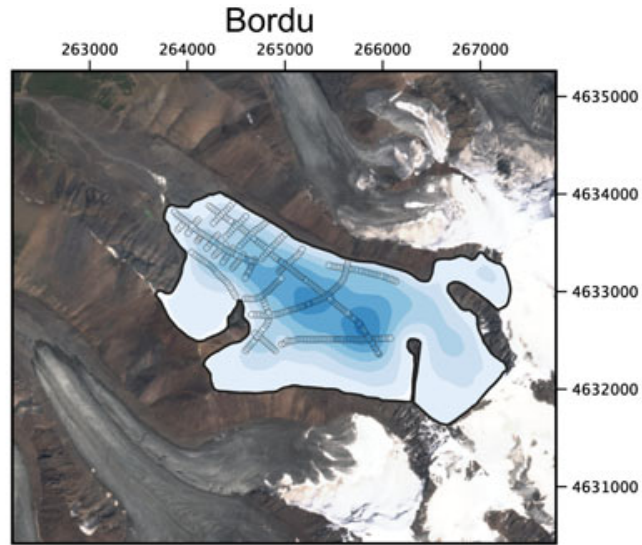

Kara-Batkak

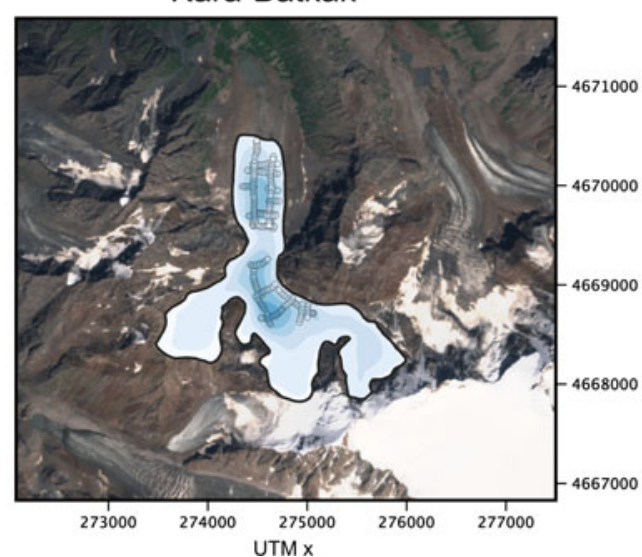

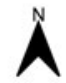

$0 \quad 5001000 \mathrm{~m}$

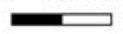

Glacier outline

Ice thickness ( $\mathrm{m}$ )

$\square<20$

$\square$ 20-40

$\square$ 40-60

ए 60-80

$\square$ 80-100

$100-120$

120-140

140-160

160-180

$>180$

Fig. 7. Composite ice thickness of the four glaciers. The locations of the ice thickness measurements are indicated with a circle. The colour of the circles corresponds to the measured ice thickness.

Table 7. Ice volumes of the composite ice thickness distribution of the selected glaciers $\left(\mathrm{km}^{3}\right)$

\begin{tabular}{lllll}
\hline & Ashu-Tor & Bordu & Golubin & Kara-Batkak \\
\hline 2017 & No data & $0.291 \pm 0.058$ & No data & $0.096 \pm 0.019$ \\
2019 & $0.389 \pm 0.078$ & No data & $0.290 \pm 0.061$ & No data
\end{tabular}

of different complexity have been developed to estimate the ice thickness without in situ data. Most published ice thickness distributions in the study area have been created based on the surface topography of the SRTM DEM and the outline of 2002. Thus, for an objective comparison of the entire ice thickness distribution, the produced composite ice thickness distributions, valid for the year in which the ice thickness measurements were performed, are recalculated back. To this end, the ice thickness distribution is derived by taking the difference between the original SRTM DEM and obtained bedrock topography. Additional areas being part of the RGI6.0 outline of 2002 and absent in the updated glacier outline and vice versa (Fig. 2) are excluded from the analysis.

\subsection{Volume-area scaling}

As a first comparison, we calculate the total ice volume of the four glaciers using a volume-area scaling approach. This is the simplest method to roughly estimate the order of magnitude of a glacier's volume (Petrakov and others, 2016). Volume-area scaling methods have been applied in a large number of studies worldwide (Grinsted, 2013). We apply the volume-area scaling formula derived for the Tien Shan from Macheret and others (1988) (V1), the formula from Bahr and others (1997) with physically justified exponents (V2) and a global formula from Grinsted (2013) (V3). All these formulas relate glacier volume to only surface area $(A$ in $\mathrm{km}^{2}$ for $V 1$ and $V 3$ and in $\mathrm{m}^{2}$ for $V 2$ ) via a power law:

$$
\begin{aligned}
& V 1=0.0298 \times A^{1.379}, \\
& V 2=0.191 \times A^{1.375}, \\
& V 3=0.0435 \times A^{1.23} .
\end{aligned}
$$

Clearly, the simple volume-area scaling formulas (Eqns (13-15)) produce ice volumes that are not too different from the values found in this study (Table 8). Only for Ashu-Tor glacier, all formulas tend to substantially underestimate the ice volume. For the other glaciers, the derived volumes are within the error bounds of the ice volume from the composite ice thickness fields. In general, the formula of Grinsted (2013) performs best, except for the volume of the Kara-Batkak glacier where the formula of Bahr and others (1997) matches most closely to the ice volume of the composite ice thickness field.

\subsection{Comparison with estimates composed without in situ data}

All the ice thickness measurements and the composite ice thickness distributions are subsequently compared with four ice thickness estimates and the consensus estimate (Farinotti and others, 2019). These were created by different models ran without the 


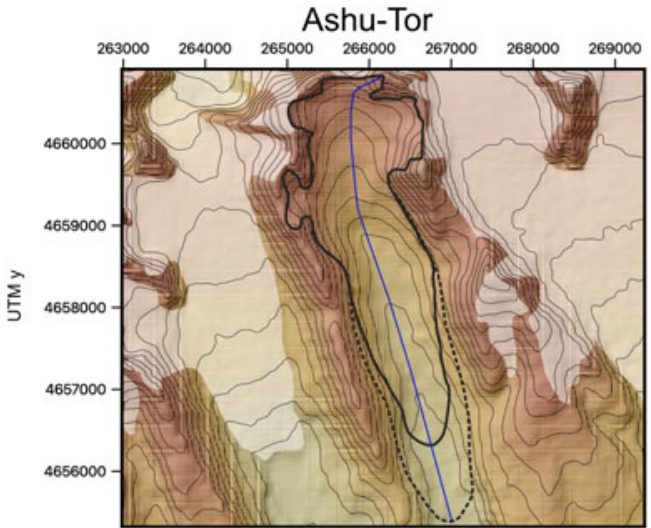

Golubin

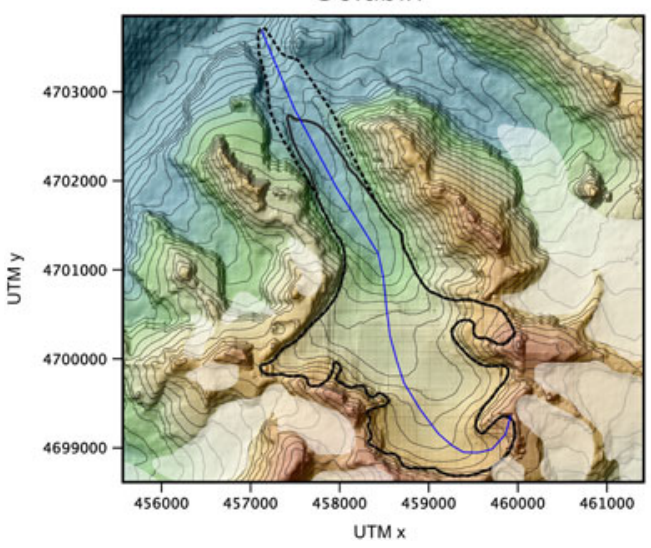

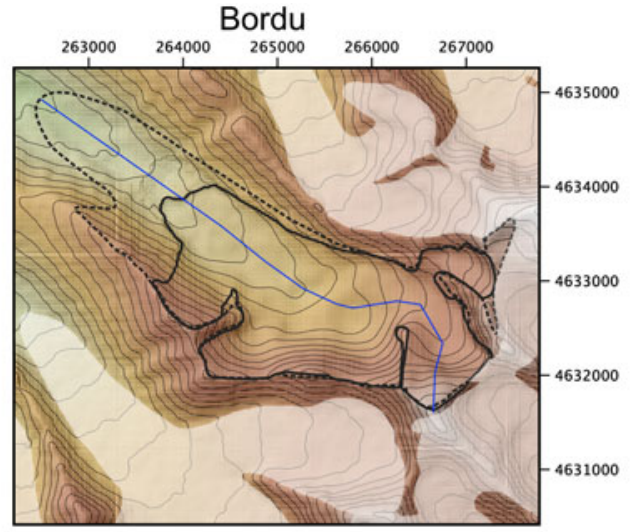

Kara-Batkak

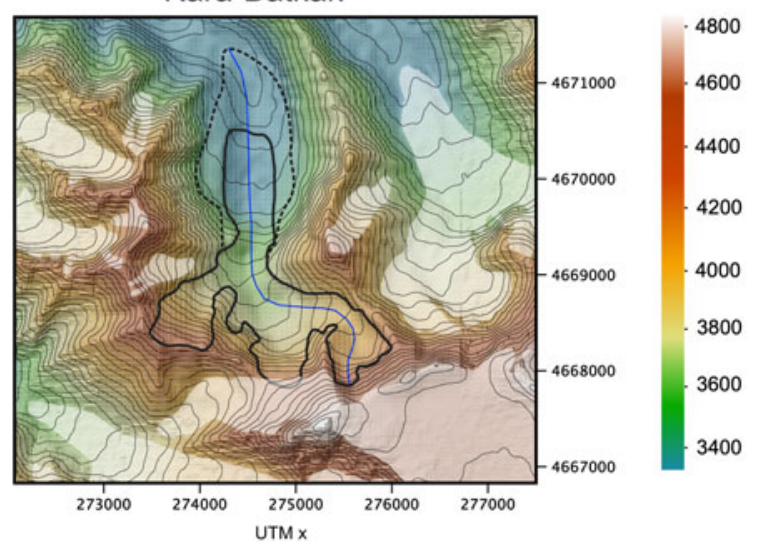

Fig. 8. Bedrock elevation and central flowline (blue line) of the different glaciers. The contours are added for every $20 \mathrm{~m}$. The LIA extent has been estimated from Sentinel-2 true colour composite images and for Golubin estimated from Aizen and others (2006).

use of in situ data and correspond to the outline in the year 2002 (RGI6.0). Therefore, the surface elevation changes between the SRTM DEM and the measured GPS position is added to the measured ice thickness for the individual measurements. The relative MAE varies between 20 and $25 \%$ for Bordu, Golubin and Kara-Batkak glaciers and $\sim 15-20 \%$ for Ashu-Tor glacier indicating a rather good correspondence (Table 9).

It is striking that for Ashu-Tor, Bordu and Golubin glaciers, the ice thickness estimated by model 1 of Huss and Farinotti (2012) matches closer to the measurements than for the consensus estimate (lower MAE). Model 3 (Maussion and others, 2019) and model 4 (Fürst and others, 2017) have typically the largest MAE and SEE. These models seem to be less appropriate to estimate the ice thickness of the selected glaciers without any measurements. This is somewhat surprising because model 3 is based on the same principles as model 1. For Kara-Batkak glacier, the MAE is clearly larger for all models (above 20\%), which is especially the case for model 3. Figure 10 indicates that model 3 clearly underestimates the ice thickness of Kara-Batkak glacier significantly while models 1 and 4 underestimate the ice thickness of this glacier less. Model 2 largely overestimates the ice thickness, which is probably associated with an overestimation of the basal shear stress. Table 9 also shows that the variability between the modelled ice thicknesses among the different models is much smaller for Ashu-Tor glacier compared to Bordu and Golubin glaciers. For Bordu glacier, the positive effect of the weighted average of the different models is most clear. The variability of the estimated ice thicknesses of the different models clearly diminishes when taking the weighted average (consensus estimate). Finally, although a good correspondence (low MAE) of the models for Ashu-Tor glacier in general, all models appear to underestimate the thickest measured ice of Ashu-Tor glacier. This might be caused by the minimum slope threshold applied by the different models, which results in a smaller maximum possible ice thickness.

\subsection{Comparison with consensus estimate}

The composite ice thickness distributions are then compared with the consensus estimates (both volume and spatial patterns) on a glacier-wide base. The total ice volumes (Table 10) corresponding to the composite ice thickness distributions for the overlapping area appear to closely match the ice volumes obtained for the consensus estimate.

Although the total ice volumes are fairly similar to the obtained volumes from the composite ice thickness distributions, there appear to be large local variations in ice thicknesses, which are depicted in Figure 11. For Ashu-Tor, Golubin and KaraBatkak glaciers, the ice thickness of the consensus estimate is clearly underestimated in the ablation area (where the measurements were performed) and (slightly) overestimated in the accumulation area.

Concerning Bordu glacier, the consensus estimate shows generally thicker ice, except for the accumulation areas. All of this suggests that the consensus estimate approximates the total ice volume well but that local ice thicknesses can vary substantially.

\subsection{Volume change between 2002 and 2017-2019}

Finally, the ice thickness distributions reconstructed in this research allow to derive an estimate of the average volume change (rates) between 2002 and the years of the field campaigns (2017 and 2019). It is clear from Table 11 that the selected glaciers lost a significant part of their ice volume of up to $-0.038 \mathrm{~km}^{3}$ 

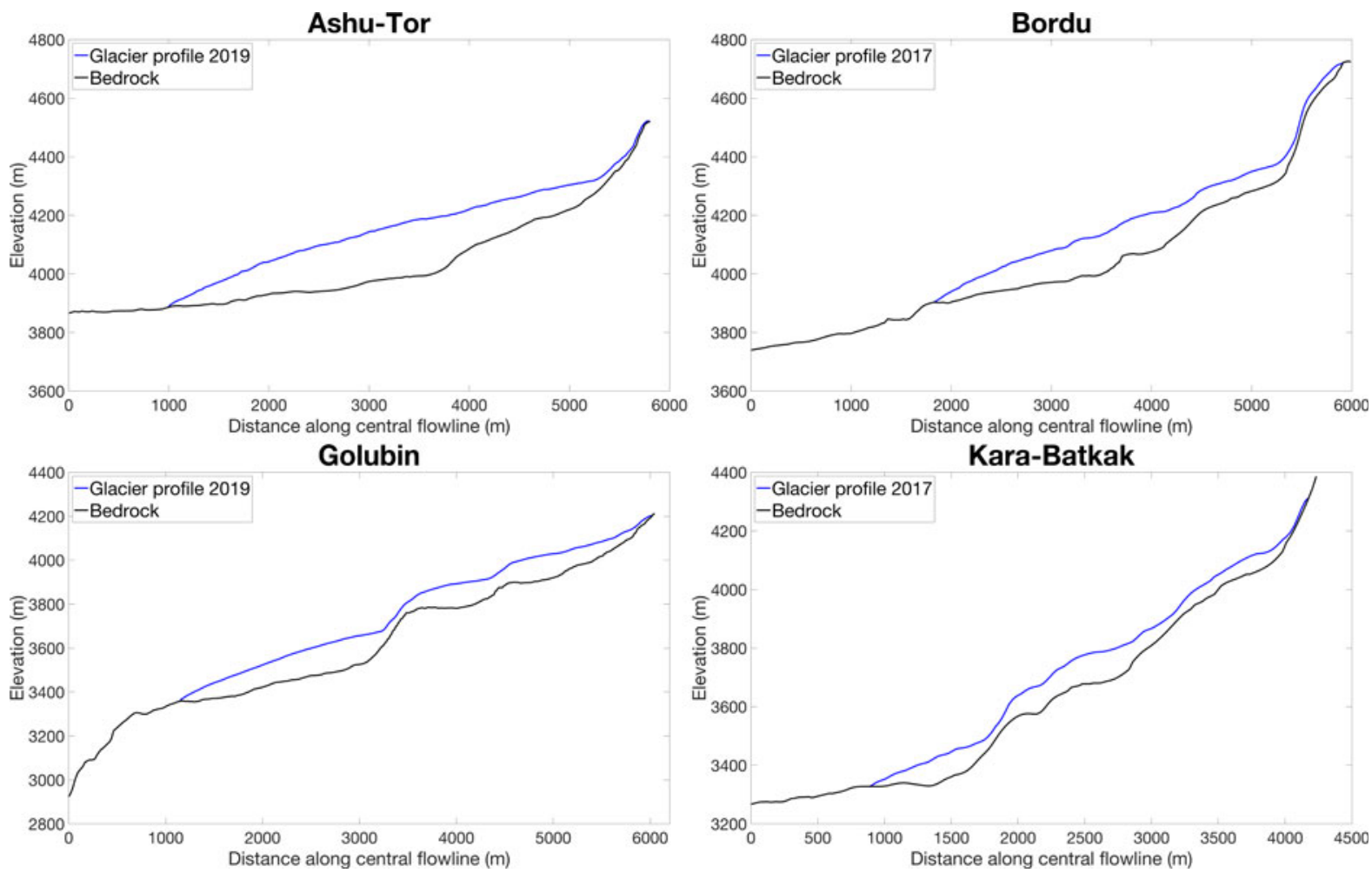

Fig. 9. Central flowline profiles of the different glaciers.

Table 8. Ice volumes of the composite ice thickness distribution valid for 2002 and calculated with the volume-area scaling formulas ( $\mathrm{km}^{3}$ )

\begin{tabular}{llll}
\hline & Ashu-Tor & Bordu & Golubin \\
\hline Composite ice thickness & $0.429 \pm 0.086$ & $0.329 \pm 0.066$ & $0.302 \pm 0.064$ \\
V1 (Macheret and others, 1988) & $0.268(-37 \%)$ & $0.276(-16 \%)$ & $0.099 \pm 0.019$ \\
V2 (Bahr and others, 1997) & $0.304(-28 \%)$ & $0.238(-21 \%)$ & $0.269(-11 \%)$ \\
V3 (Grinsted, 2013) & $0.309(-27 \%)$ & $0.313(-5 \%)$ & $0.277(-8 \%)$ \\
\hline
\end{tabular}

Table 9. The relative MAE and the relative SEE between the measured ice thicknesses and the ice thicknesses of four independent ice thickness distributions and the consensus estimate (Farinotti and others, 2019)

\begin{tabular}{|c|c|c|c|c|c|c|c|c|}
\hline & \multicolumn{2}{|c|}{ Ashu-Tor } & \multicolumn{2}{|c|}{ Bordu } & \multicolumn{2}{|c|}{ Golubin } & \multicolumn{2}{|c|}{ Kara-Batkak } \\
\hline & MAE & SEE & MAE & SEE & MAE & SEE & MAE & SEE \\
\hline Consensus estimate (Farinotti and others, 2019) & $18.07^{3}$ & 25.01 & $16.78^{2}$ & 19.51 & $19.79^{3}$ & 24.06 & $23.24^{2}$ & 27.57 \\
\hline Model 1 (Huss and Farinotti, 2012) & $14.35^{1}$ & 20.41 & $16.75^{1}$ & 20.27 & $17.91^{1}$ & 23.75 & $24.30^{3}$ & 28.45 \\
\hline Model 2 (Frey and others, 2014) & $17.38^{2}$ & 24.04 & $23.90^{4}$ & 28.55 & $19.51^{2}$ & 25.50 & $21.88^{1}$ & 25.89 \\
\hline Model 3 (Maussion and others, 2019) & $24.25^{5}$ & 34.47 & $18.46^{3}$ & 21.21 & $21.14^{4}$ & 25.98 & $36.06^{5}$ & 41.07 \\
\hline Model 4 (Fürst and others, 2017) & $18.27^{4}$ & 24.27 & $29.95^{5}$ & 35.31 & $24.34^{5}$ & 27.99 & $24.48^{4}$ & 29.91 \\
\hline
\end{tabular}

The numbers in superscript indicate the ranking of the different models (1 is best).

$(-13 \%)$ for Bordu glacier. Golubin glacier lost a smaller fraction of its total ice volume (only $-0.012 \mathrm{~km}^{3}$ or $-4.1 \%$ ). Ashu-Tor glacier lost $\sim 0.04 \mathrm{~km}^{3}(-10.3 \%)$ over 17 years, which is close to the ice volume decrease of $0.06 \mathrm{~km}^{3}$ observed between 1977 and 2000 based on DEM differencing (Kutuzov, 2015). Kara-Batkak glacier, finally, lost only $0.003 \mathrm{~km}^{3}$, which corresponds to $\sim 3 \%$ of its total volume. The ice volume change rates (volume change/number of years) lie between $-0.2 \%$ for Kara-Batkak glacier and $-0.8 \%$ for Bordu glacier. These numbers are somewhat larger than the average loss rates $(-0.3 \%)$ reported in the Tien Shan mountains over the past half-century (Sorg and others, 2012), which might point at an increase in glaciers mass loss for the selected glaciers. Furthermore, Table 11 indicates that Ashu-Tor and Bordu glaciers located in the Inner Tien Shan, where glacier retreat is expected to be more limited due to a lower mass turnover, appear to have lost a larger fraction of their ice volume as compared to Golubin and Kara-Batkak glacier.

\section{Discussion}

Despite the large importance of glaciers in the Tien Shan, to date, a limited amount of in situ ice thickness measurements has been published. One of the consequences is the larger spread of ice thickness estimations for glaciers in this mountain range compared to other well-measured mountain ranges such as the European Alps (Farinotti and others, 2019). For instance, we found that different independent estimates and the consensus estimate for the four selected Kyrgyz glaciers differ by up to $300 \%$ at the local scale (Fig. 10) . The present study used in situ ice thickness measurements and various reconstruction 

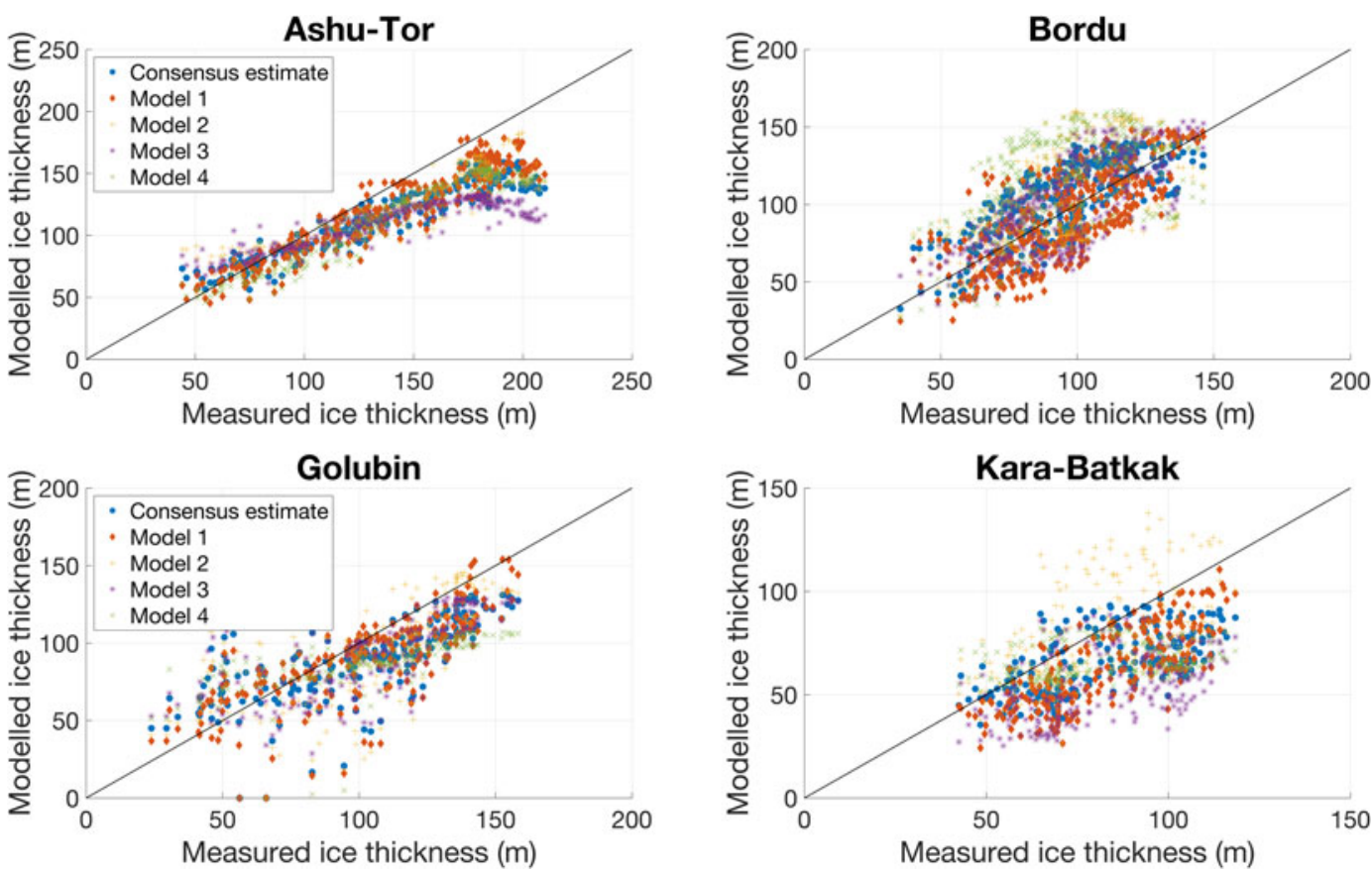

Fig. 10. The difference between modelled and measured ice thickness for the estimates and the consensus estimate presented in Farinotti and others (2019).

Table 10. Ice volume of the different glaciers, corresponding to the year 2002 $\left(\mathrm{km}^{3}\right)$

\begin{tabular}{lllll}
\hline & Ashu-Tor & Bordu & Golubin & Kara-Batkak \\
\hline Composite ice thickness & $0.429 \pm$ & $0.329 \pm$ & $0.302 \pm$ & $0.099 \pm$ \\
(2002) & 0.086 & 0.066 & 0.064 & 0.019 \\
Consensus estimate (2002) & 0.437 & 0.358 & 0.330 & 0.085 \\
(Farinotti and others, 2019) & & & & \\
\hline
\end{tabular}

approaches to obtain a detailed ice thickness distribution of four glaciers in the Tien Shan.

\subsection{Differences in applied ice thickness models using in situ data}

The individually modelled ice thicknesses, obtained by the three models with the same set of measurements for calibration, varied substantially (Fig. 12). Only in the areas with RES measurements, where the ice thickness models are constrained strongly, the individual results matched closely. Generally, differences between the modelled ice thickness increase further away from the RES measurements. For Ashu-Tor and for Golubin glaciers, for instance, modelled ice thicknesses differ considerably with measurement differences up to $100 \mathrm{~m}$. This is mainly caused by the yield stress model which produces much thicker ice $(>50-100 \mathrm{~m}$ thicker) in the upper part of the glaciers (especially in the accumulation areas). The modelled ice thicknesses of Golubin glacier using the GlabTop model resulted likewise in thicker ice (Bolch, 2015). This can be explained by the very small local slope in this area (Li and others, 2012). Moreover, a dominant source of uncertainty for the yield stress model is the absence of RES measurements in the accumulation areas. The RES measurements were, (almost) all, performed in crevasse-free, flat and thus thicker glacier parts associated with compressing flow. This might cause a bias towards higher thickness values where the ice is mainly diverging (Frey and others, 2010). A solution would be to let the ascribed yield stress vary (increase or decrease) towards particular areas as was done in Zekollari and others (2013). Concerning Bordu and Kara-Batkak glaciers, on the other hand, the mass flux 2D model calculates thicker ice, especially along the margins of the glaciers and in the accumulation areas. This can directly be attributed to the larger ice flux in the steeper areas where the plastic flow assumption in the yield stress model reduces the estimated ice thickness (Fig. 12). In addition, only the mass flux 2D model calibrates the flow parameter which might be an important issue for polythermal glaciers (Farinotti and others, 2017).

The mass flux models' main uncertainty is introduced by the calculation of the AMB. Both models use $\mathrm{d} h / \mathrm{d} t$ rates derived from DEM differences and linear SMB gradients derived from individual SMB measurements. Nevertheless, SMB gradients appear to often have a more complex character, especially in the accumulation areas. The inconsistencies that may arise between the $\mathrm{d} h / \mathrm{d} t$ fields and SMB depending solely on elevation might substantially have influenced the derived AMB. However, it was found by Farinotti and others (2009) and Helfricht and others (2019) that the final result of this approach is not very sensitive to changes in the AMB.

\subsection{Ice thickness estimates without in situ data}

In general, the ice volumes obtained using the volume-area scaling formulas (Macheret and others, 1988; Bahr and others, 1997; Grinsted, 2013) and the consensus estimate of Farinotti and others (2019) match closely to the ice volumes of the composite ice thickness distributions and to the observations of the ITMIX experiment (Farinotti and others, 2017). However, our results reveal larger differences concerning local ice thicknesses. We found for instance that the published estimates reconstructed without in situ data all underestimate the maximum ice thickness of Ashu-Tor glacier significantly (>25\%). Although this seems very high, it is still within the bounds of $30 \%$ which is often cited for maximum local ice thickness error (Huss and Farinotti, 2012; Helfricht and others, 2019). We also noticed a smaller spread between the different estimates and our measurements for Ashu-Tor and Golubin glaciers compared to Kara-Batkak and Bordu glaciers. This suggests a lower dependency on the model type to estimate the ice thickness of these glaciers (Fig. 10). A similar finding could be noticed in Figure 6. Therefore, the performance of ice thickness models, applied 


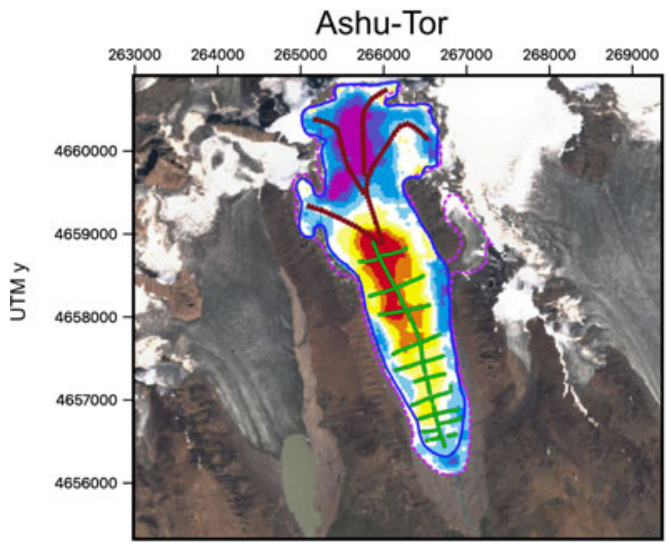

Golubin

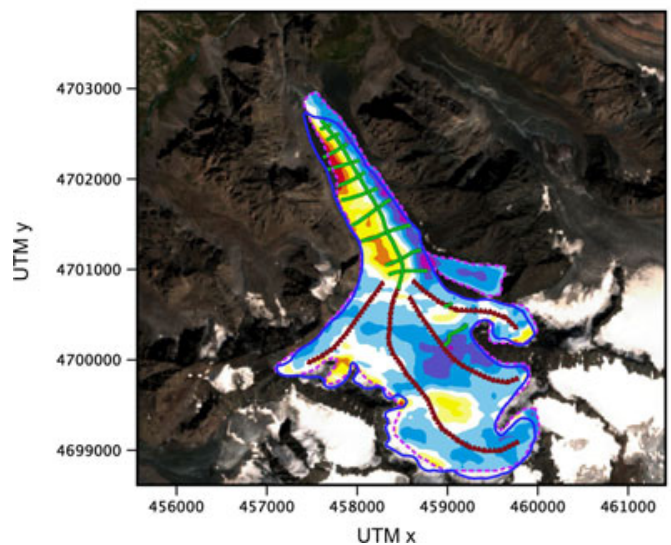

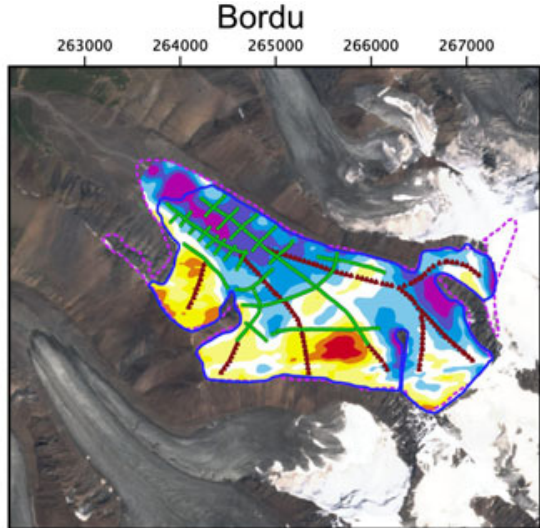
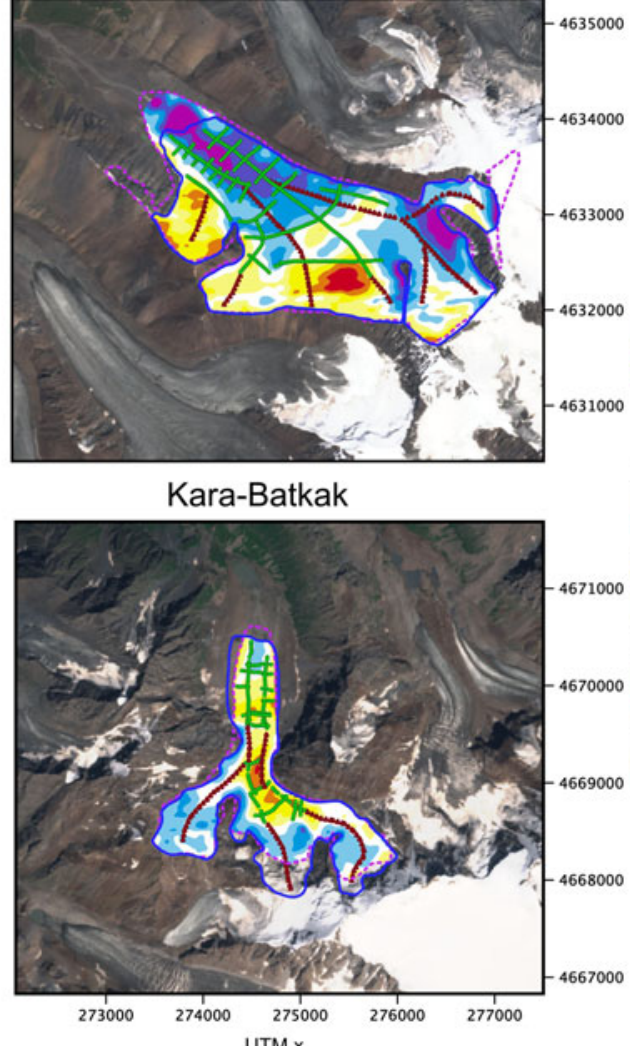

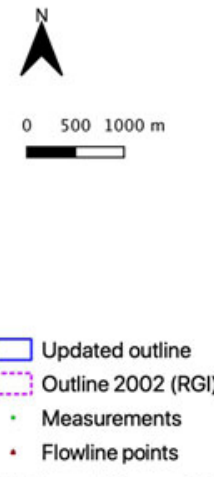

Thickness difference (m)

- $<-35$

-35 to -25

-25 to -15

ए -15 to -5

ए -5 to 5

5 to 15

15 to 25

25 to 35

- 35

Fig. 11. Difference between the ice thickness field of the consensus estimate and the composite ice thickness field obtained in this paper, referring to the state in 2002.

Table 11. Ice volume of the different glaciers in 2002 (adjusted outlines) and at the time of the field campaigns $\left(\mathrm{km}^{3}\right)$

\begin{tabular}{llll}
\hline & Ashu-Tor & Bordu & Golubin \\
\hline 2002 & $0.429 \pm 0.086$ & $0.329 \pm 0.066$ & $0.302 \pm 0.064$ \\
2017 & No data & $0.291 \pm 0.058$ & No data \\
2019 & $0.389 \pm 0.078$ & No data & $0.099 \pm 0.019$ \\
Volume change & $-10.3 \%$ & $-13.0 \%$ & $0.096 \pm 0.019$ \\
Volume change rate & $-0.6 \% \mathrm{a}^{-1}$ & $-0.8 \% \mathrm{a}^{-1}$ & $-4.1 \%$ \\
\hline
\end{tabular}

with or without the use of in situ data, appears to depend strongly on the glacier size, type and characteristics. While Ashu-Tor glacier is a typical glacier tongue and rather flat (and differences between the modelled ice thicknesses are smaller), the shape of Kara-Batkak glacier is much more complex (and differences are much larger). Concerning the different estimates, our results revealed that the model of Huss and Farinotti (2012) matches more closely to the measured ice thicknesses compared to the consensus estimate. Hence, it might be preferable to use this model to estimate the ice thickness for unmeasured glaciers in our study area. Models 3 and 4 appeared to match less closely to the measurements. However, model 4 (Fürst and others, 2017), calibrated by the ice thickness measurements (corresponding to the mass flux 2D model in this paper) performed significantly better. This highlights strongly the necessity of in situ data for model calibration and associated model performance.

\section{Conclusion}

The goal of this research was to obtain an accurate and highly detailed ice thickness distribution of Ashu-Tor, Bordu, Golubin and Kara-Batkak glaciers in the Kyrgyz Tien Shan mountains, which can be used for glacier modelling and to assess water storage. Multiple field campaigns were performed to measure the ice thickness of the glaciers with a RES system. The thickest ice was measured on Ashu-Tor with a maximum of $201 \pm 12 \mathrm{~m}$. However, limited accessibility in particular areas of the glaciers, due to crevasses, ice falls and snow cover, hindered full coverage with RES measurements. Hence, three different ice thickness models (yield stress model, mass flux flowline model, mass flux 2D model), calibrated with the measurements, were applied to obtain the ice thickness in the unmeasured areas. Since the modelled ice thicknesses differed considerably and no preferred method could be determined for all four glaciers, a weighted average was assembled to obtain a composite ice thickness distribution. The weights were derived from a performance assessment using a cross-correlation approach between modelled and measured ice thicknesses for a subset of the measurements. For all glaciers, we found that the mass flux 2D model (Fürst and others, 2017) had the lowest errors. Consequently, this model was given the largest weight. A comparison of the ice thickness fields derived in this paper with estimates produced without any in 

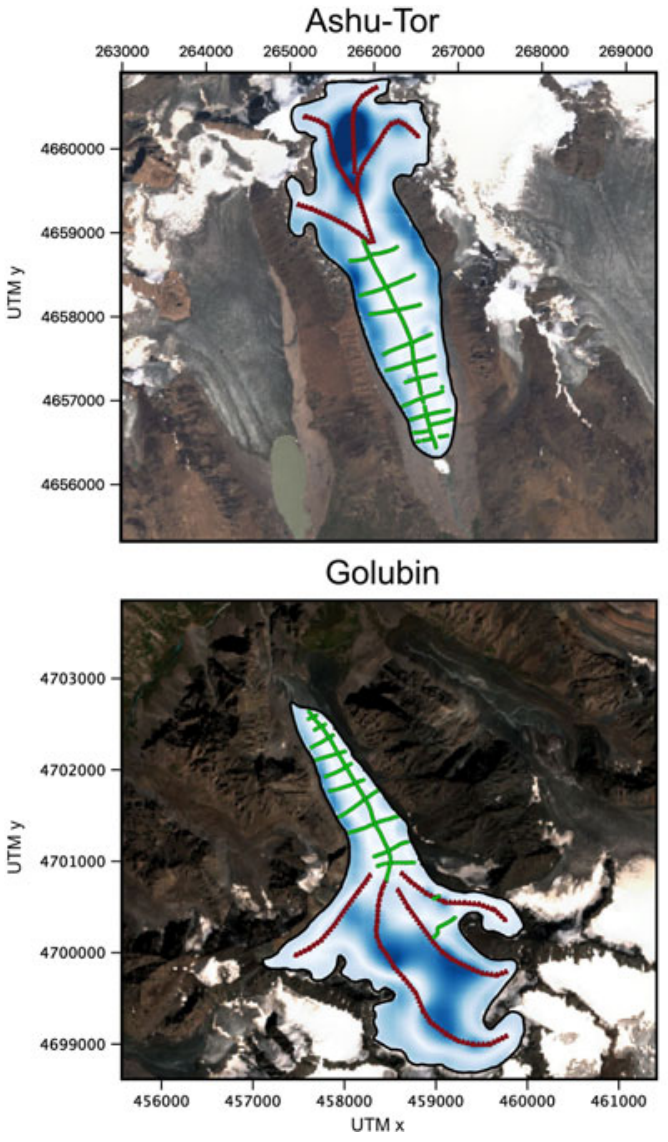
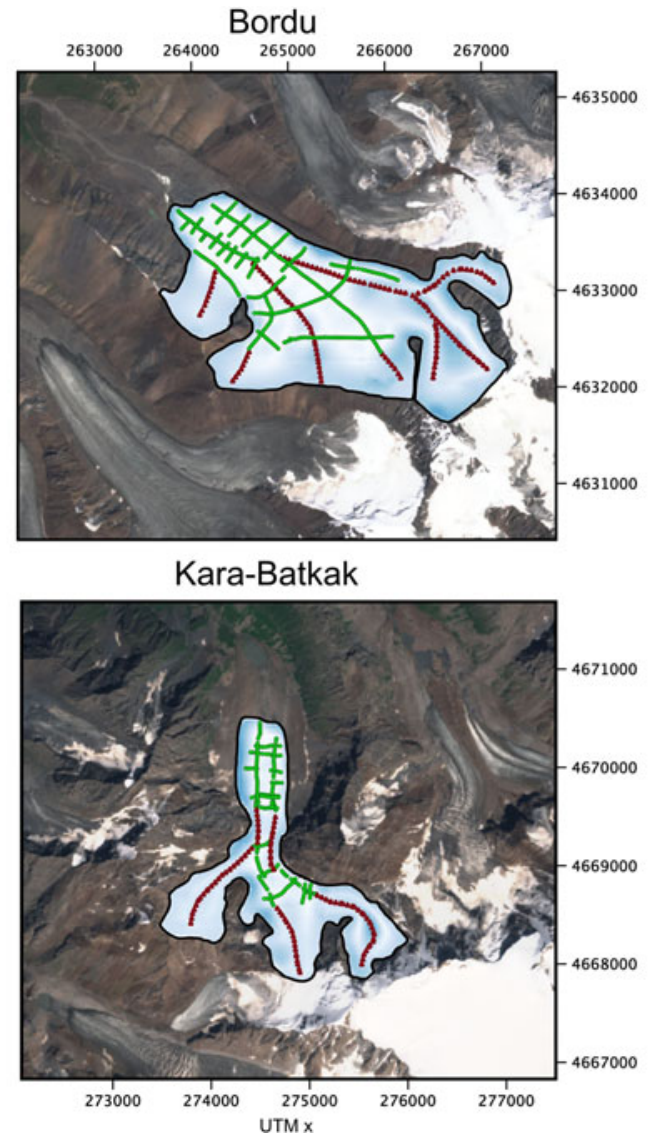
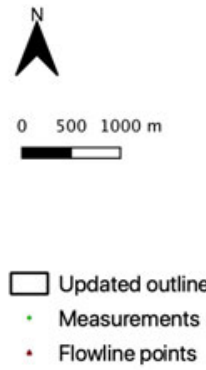

$\operatorname{Max}-\operatorname{Min}(\mathrm{m})$

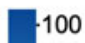

75

50

25

0

Fig. 12. Difference between the maximum and the minimum modelled ice thickness from all three calibrated models.

situ data revealed that these estimates approach the total ice volume well but exhibit significant deviations at the local scale. This leads us to conclude that accurate measurements remain necessary for detailed analyses and models. For more general purposes and to assess ice volume, however, estimates of glacier ice thickness without in situ data seem to have sufficient quality in the study area.

\section{Data}

All the ice thickness measurements will be submitted to the GlaThiDa (https://www.gtn-g.ch/glathida/) to allow the glaciological community to use the in situ data to optimize the ice thickness models in Central Asia. The adjusted outlines of the glaciers, the DEMs and all the other input data will be provided on request by the first author.

Acknowledgements. We thank Erlan Azisov from the Central Asian Institute of Applied Geosciences (CAIAG) and Martina Barandun from Université de Fribourg for providing the SMB data of Golubin glacier. O.R. was supported by the RFBR grant No. 20-05-00681. Results produced by J.J.F. are based on numerical simulations conducted at the high-performance computing centre of the Regionales Rechenzentrum Erlangen (RRZE) of the University of Erlangen-Nürnberg. Lander Van Tricht holds a PhD fellowship of the Research Foundation-Flanders (FWO-Vlaanderen).

\section{References}

Aizen VB, Aizen EM, Melack JM and Dozier J (1997) Climatic and hydrologic changes in the Tien Shan, Central Asia. Journal of Climate 10, 13931404. doi: 10.1175/1520-0442(1997)0102.0.CO;2.

Aizen VB, Kuzmichenok VA, Surazakov AB and Aizen EM (2006) Glacier changes in the central and northern Tien Shan during the last 140 years based on surface and remote-sensing data. Annals of Glaciology 43, 202-213. doi: 10.3189/172756406781812465.
Aizen VB, Kuzmichenok VA, Surazakov AB and Aizen EM (2007) Glacier changes in the Tien Shan as determined from topographic and remotely sensed data. Global and Planetary Change 56, 328-340. doi: 10.1016/j.gloplacha.2006. 07.016.

Aizen VB and Zakharov VG (1989) Mass balance and ice flow velocity of Davydov Glacier basing on research in 1984-1985. Data of Glaciological Studies 67, 197-202. [in Russian].

Andreassen LM, Huss M, Melvold K, Elvehøy H and Winsvold SH (2015) Ice thickness measurements and volume estimates for glaciers in Norway. Journal of Glaciology 61(228), 763-775. doi: 10.3189/2015JoG14J161.

Bahr DB, Meier MF and Peckham SD (1997) The physical basis of glacier volume-area scaling. Journal of Geophysical Research 102, 20355-20362. doi: 10.1029/97JB01696.

Baojuan H, Weijun S, Yetang W and Zhongqin L (2017) Glacier shrinkage in the Chinese Tien Shan Mountains from 1959/1972 to 2010/2012. Arctic, Antarctic, and Alpine Research 49(2), 213-225. doi: 10.1657/AAAR0015-032.

Barandun M and 7 others (2018) Multi-decadal mass balance series of three Kyrgyz glaciers inferred from modelling constrained with repeated snow line observations. The Cryosphere 12, 1899-1919. doi: 10.5194/ tc-12-1899-2018.

Binder D and 5 others (2009) Determination of total ice volume and ice-thickness distribution of two glaciers in the Hohe Tauern region, Eastern Alps, from GPR data. Annals of Glaciology 50(51), 71-79. doi: $10.3189 / 172756409789097522$.

Bolch T (2007) Climate change and glacier retreat in northern Tien Shan (Kazakhstan/Kyrgyzstan) using remote sensing data. Global and Planetary Change 56(1-2), 1-12. doi: 10.1016/j.gloplacha.2006.07.009.

Bolch T (2015) Glacier area and mass changes since 1964 in the Ala Archa Valley, Kyrgyz Ala-Too, northern Tien Shan. Ice and Snow 55, 28-39. doi: 10.15356/IS.2015.01.03.

Brandt O, Kohler J and Lüthje M (2008) Spatial mapping of multi-year superimposed ice on the glacier Kongsvegen, Svalbard. Journal of Glaciology 54(184), 73-80. doi: 10.3189/002214308784409080.

Braun $\mathbf{M}$ and 8 others (2019) Constraining glacier elevation and mass changes in South America. Nature Climate Change 9, 130-136. doi: 10.1038/ s41558-018-0375-7. 
Carrivick JL, Davies BJ, James WHM, Quincey DJ and Glasser NF (2016) Distributed ice thickness and glacier volume in southern South America. Global and Planetary Change 146, 122-132. doi: 10.1016/j.gloplacha.2016. 09.010 .

Dyurgerov MB and 5 others (1994) On the cause of glacier mass balance variations in the Tien Shan mountains. GeoJournal 33(2-3), 311-317. doi: 10. 1007/BF00812879.

Engel Z, Šobr M and Yerokhin SA (2012) Changes of Petrov glacier and its proglacial lake in the Akshiirak massif, central Tien Shan, since 1977. Journal of Glaciology 58(208), 388-398. doi: 10.3189/2012JoG11J085.

Farías-Barahona D and 9 others (2020) Detailed quantification of glacier elevation and mass changes in South Georgia. Environmental Research Letters 15(3). doi: 10.1088/1748-9326/ab6b32.

Farinotti D and 7 others (2015) Substantial glacier mass loss in the Tien Shan over the past 50 years. Nature Geoscience 8(9), 716-722. doi: 10.1038/ngeo2513.

Farinotti D and 36 others (2017) How accurate are estimates of glacier ice thickness? Results from ITMIX, the Ice Thickness Models Intercomparison eXperiment. The Cryosphere 11(2), 949-970. doi: 10.5194/tc-11-949-2017.

Farinotti D and 6 others (2019) A consensus estimate for the ice thickness distribution of all glaciers on Earth. Nature Geoscience 12, 168-173. doi: 10.1038/s41561-019-0300-3.

Farinotti D, Huss M, Bauder A, Funk M and Truffer M (2009) A method to estimate the ice volume and ice-thickness distribution of alpine glaciers. Journal of Glaciology 55(191). doi: 10.3189/002214309788816759.

Fischer A (2009) Calculation of glacier volume from sparse ice-thickness data, applied to Schaufelferner, Austria. Journal of Glaciology 55(191), 453-460. doi: 10.3189/002214309788816740.

Fountain A, Raymond CF and Nakao M (2000) Debris-covered glaciers. Proceedings of an International Workshop held at the University of Washington in Seattle, Washington, USA, 13-15 September 2000. IAHS-AISH Publ. (264), 288.

Frey $\mathbf{H}$ and 9 others (2014) Estimating the volume of glaciers in the Himalayan-Karakoram region using different methods. The Cryosphere $\mathbf{8}$ (6), 2313-2333. doi: 10.5194/tc-8-2313-2014.

Frey H, Haeberli W, Linsbauer A, Huggel C and Paul F (2010) A multi-level strategy for anticipating future glacier lake formation and associated hazard potentials. Natural Hazards Earth System Sciences 10(2), 339-352. doi: 10. 5194/nhess-10-339-2010.

Fürst JJ and 14 others (2017) Application of a two-step approach for mapping ice thickness to various glacier types on Svalbard. The Cryosphere 11(5), 2003-2032. doi: 10.5194/tc-11-2003-2017.

Fürst JJ and 24 others (2018) The ice-free topography of Svalbard. Geophysical Research Letters 45(21), 11760-11769. doi: 10.1029/ 2018GL079734

Gärtner-Roer I and 5 others (2014) A database of worldwide glacier thickness observations. Global and Planetary Change 122, 330-344. doi: 10.1016/j. gloplacha.2014.09.003.

Gindraux S, Boesch R and Farinotti D (2017) Accuracy assessment of digital surface models from unmanned aerial vehicles imagery on glaciers. Remote Sensing 9(2), 186. doi: 10.3390/rs9020186.

Grinsted A (2013) An estimate of global glacier volume. The Cryosphere 7, 141-151. doi: 10.5194/tc-7-141-2013.

Haeberli W and Hoelzle M (1995) Application of inventory data for estimating characteristics of and regional climate-change effects on mountain glaciers: a pilot study with the European Alps. Annals of Glaciology 21, 206212. doi: $10.1017 /$ S0260305500015834.

Hagg WJ, Braun LN, Uvarov VN and Makarevich KG (2004) A comparison of three methods of mass-balance determination in the Tuyuksu glacier region, Tien Shan, Central Asia. Journal of Glaciology 50(171), 505-510. doi:10.3189/172756504781829783.

Hagg W, Mayer C, Lambrecht A, Kriegel D and Azizov E (2013) Glacier changes in the Big Naryn basin, Central Tian Shan. Global and Planetary Change 110, 40-50. doi: 10.1016/j.gloplacha.2012.07.010.

Helfricht K, Huss M, Fischer A and Otto JC (2019) Calibrated ice thickness estimate for all glaciers in Austria. Frontiers of Earth Science 7. doi: 10.3389/ feart.2019.00068

Hoelzle M and 20 others (2017) Re-establishing glacier monitoring in Kyrgyzstan and Uzbekistan, Central Asia. Geoscientific Instrumentation, Methods and Data Systems 6(2), 397-418. doi: 10.5194/gi-6-397-2017.

Huss M and Farinotti D (2012) Distributed ice thickness and volume of all glaciers around the globe. Journal of Geophysical Research: Earth Surface 117(F4). doi: 10.1029/2012JF002523.
Huss $\mathbf{M}$ and Hock R (2018) Global-scale hydrological response to future glacier mass loss. Nature Climate Change 8(2), 135-140. doi: 10.1038/ s41558-017-0049-x.

Hutchinson MF (1989) A new procedure for gridding elevation and stream line data with automatic removal of spurious pits. Journal of Hydrology 106(3-4), 211-232. doi: 10.1016/0022-1694(89)90073-5

Immerzeel WW and Bierkens MFP (2012) Asia's water balance. Nature Geoscience 5(12), 841-842. doi: 10.1038/ngeo1643.

Immerzeel WW, van Beek LPH and Bierkens MFP (2010) Climate change will affect the Asian water towers. Science (New York, N.Y.) 328(5984), 1382-1385. doi: 10.1126/science.1183188.

Jacob T, Wahr J, Pfeffer WT and Swenson S (2012) Recent contributions of glaciers and ice caps to sea level rise. Nature 482(7386), 514-518. doi: 10. 1038/nature10847.

Kääb A (2011) Natural hazards associated with glaciers and permafrost. In Singh VP Singh P and Haritashya UK eds. Encyclopedia of earth sciences series. Dordrecht: Springer Netherlands, pp. 763-775. doi: 10.1007/ 978-90-481-2642-2_368.

Kääb A, Reynolds JM and Haeberli W (2005) Glacier and permafrost hazards in high mountains. In Huber UM Bugmann HKM and Reasoner MA eds. Global Change and Mountain Regions - A State of Knowledge Overview. Dordrecht: The Mountain Research Initiative. Kluwer, pp. 225-234. doi: 10.1007/1-4020-3508-x_23.

Kenzhebaev R and 5 others (2017) Mass balance observations and reconstruction for Batysh Sook Glacier, Tien Shan, from 2004 to 2016. Cold Regions Science and Technology 135, 76-89. doi: 10.1016/J.COLDREGIONS.2016.12.007.

Khromova TE, Dyurgerov MB and Barry RG (2003) Late-twentieth century changes in glacier extent in the Ak-shirak range, Central Asia, determined from historical data and ASTER imagery. Geophysical Research Letters 30 (16). doi: 10.1029/2003GL017233.

Kraaijenbrink PDA, Bierkens MFP, Lutz AF and Immerzeel WW (2017) Impact of a global temperature rise of 1.5 degrees Celsius on Asia's glaciers. Nature 549(7671), 257-260. doi: 10.1038/nature23878.

Kronenberg $\mathbf{M}$ and 9 others (2016) Mass-balance reconstruction for Glacier No. 354, Tien Shan, from 2003 to 2014. Annals of Glaciology 57(71), 92102. doi: 10.3189/2016AoG71A032

Kutuzov SS (2015) Changes in glacier area and volume in Terskey Ala-Too range in the second half of XX century. Ice and Snow 117(1), 5. doi: 10. 15356/2076-6734-2012-1-5-14.

Kutuzov S, Thompson LG, Lavrentiev I and Tian L (2018) Ice thickness measurements of Guliya ice cap, western Kunlun Mountains (Tibetan Plateau), China. Journal of Glaciology 64(248), 977-989. doi: 10.1017/jog.2018.91.

Lambrecht A, Mayer C, Aizen V, Floricioiu D and Surazakov A (2014) The evolution of Fedchenko glacier in the Pamir, Tajikistan, during the past eight decades. Journal of Glaciology 60(220), 233-244. doi: 10.3189/ 2014JoG13J110.

Langhammer L, Grab M, Bauder A and Maurer H (2019) Glacier thickness estimations of alpine glaciers using data and modeling constraints. The Cryosphere 13, 2189-2202. doi: 10.5194/tc-13-2189-2019.

Lapazaran JJ, Otero J, Martín-Español A and Navarro FJ (2016) On the errors involved in ice-thickness estimates I: ground-penetrating radar measurement errors. Journal of Glaciology 62(236), 1008-1020. doi: 10.1017/jog. 2016.93.

Lavrentiev II and 5 others (2014) Russian-Kyrgyz radio echo-sounding studies of the Tien Shan glaciers during last years. Materials of International Conference 'Remote- and Ground-based Earth Observations in Central Asia' Bishkek, Kyrgyzstan, September 8-9, pp. 330-336 [in Russian].

Li H, Ng F, Li Z, Qin D and Cheng G (2012) An extended 'perfect-plasticity' method for estimating ice thickness along the flow line of mountain glaciers. Journal of Geophysical Research: Earth Surface 117(F1). doi: 10. 1029/2011JF002104.

Linsbauer A, Paul F and Haeberli W (2012) Modeling glacier thickness distribution and bed topography over entire mountain ranges with GlabTop: application of a fast and robust approach. Journal of Geophysical Research: Earth Surface 117(F3). doi: 10.1029/2011JF002313.

Linsbauer A, Paul F, Hoelzle M, Frey H and Haeberli W (2009) The Swiss Alps without glaciers - a GIS-based modelling approach for reconstruction of glacier beds. Proceedings of Geomorphometry 2009, pp. 243-247. doi: 10. 5167/uzh-27834

Lippl S and 5 others (2019) Uncertainty assessment of ice discharge using GPR-derived ice thickness from Gourdon Glacier, Antarctic Peninsula. Geosciences 10(1), 12. doi: 10.3390/geosciences10010012. 
Luo Y and 8 others (2018) Contrasting streamflow regimes induced by melting glaciers across the Tien Shan-Pamir-North Karakoram. Scientific Reports 8(1), 16470. doi: 10.1038/s41598-018-34829-2.

Macheret YY, Cherkasov PA and Bobrova LI (1988) Tolschina i ob'em lednikov djungarskogo alatau po danniy aeroradiozondirovaniya. Data of Glaciological Studies 62, 59-71. [in Russian]

Marshall SJ and 7 others (2011) Glacier water resources on the eastern slopes of the Canadian Rocky Mountains. Canadian Water Resources Journal 36 (2), 109-134

Maussion F and 14 others (2019) The Open Global Glacier Model (OGGM) v1.1. Geoscientific Model Development 12(3), 909-931. doi: 10.5194/ gmd-12-909-2019.

Mouginot J, Rignot E, Gim Y, Kirchner D and Le Meur E (2008) Low-frequency radar sounding of ice in East Antarctica and southern Greenland. Annals of Glaciology 55(67), 138-146. doi: 10.3189/2014AoG67A089.

Nagai H, Fujita K, Sakai A, Nuimura T and Tadono T (2016) Comparison of multiple glacier inventories with a new inventory derived from highresolution ALOS imagery in the Bhutan Himalaya. The Cryosphere 10(1), 65-85. doi: 10.5194/tc-10-65-2016.

Narod BB and Clarke GKC (1994) Miniature high-power impulse transmitter for radio-echo sounding. Journal of Glaciology 40(134), 190-194. doi: 10. 3189/s002214300000397x.

Nosenko GA, Lavrentiev II, Glazovskii AF, Kazatkin NE and Kokarev AL (2016) The polythermal structure of Central Tuyuksu glacier. Earth's Cryosphere 20(4), 105-115. doi: 10.21782/KZ1560-7496-2016-4(105-115).

Osmonov A, Bolch T, Xi C, Kurban A and Guo W (2013) Glacier characteristics and changes in the Sary-Jaz river basin (Central Tien Shan, Kyrgyzstan) - 1990-2010. Remote Sensing Letters 4(8), 725-734. doi: 10. 1080/2150704X.2013.789146.

Pattyn F and 6 others (2003) Ice dynamics and basal properties of Sofiyskiy glacier, Altai mountains, Russia, based on DGPS and radio-echo sounding surveys. Annals of Glaciology 37, 286-292. doi: 10.3189/172756403781815627.

Paul F and 19 others (2013) On the accuracy of glacier outlines derived from remote-sensing data. Annals of Glaciology 54(63), 171-182. doi: 10.3189/ 2013AoG63A296.

Petrakov DA and 8 others (2016) Accelerated glacier shrinkage in the Ak-Shyirak massif, Inner Tien Shan, during 2003-2013. The Science of the Total Environment 562, 364-378. doi: 10.1016/j.scitotenv.2016.03.162.

Petrakov DA, Kovalenko NV, Lavrentiev II and Usubaliev RA (2014) Ice thickness, volume and current changes of the Sary-Tor Glacier area (Ak-Shyirak massif, Inner TianShan). Earth's Cryosphere 18(3), 83-91.

Pieczonka T, Bolch T, Kröhnert M, Peters J and Liu S (2018) Glacier branch lines and glacier ice thickness estimation for debris-covered glaciers in the Central Tien Shan. Journal of Glaciology 64(247), 835-849. doi: 10.1017/jog. 2018.75.

Pritchard HD (2019) Asia's shrinking glaciers protect large populations from drought stress. Nature 569, 649-654. doi: 10.1038/s41586-019-1240-1.

Quincey D and 9 others (2018) The changing water cycle: the need for an integrated assessment of the resilience to changes in water supply in High-Mountain Asia. Wiley Interdisciplinary Reviews: Water 5(1), e1258. doi: $10.1002 /$ wat2.1258.

Racoviteanu AE, Paul F, Raup B, Khalsa SJS and Armstrong R (2009) Challenges and recommendations in mapping of glacier parameters from space: results of the 2008 Global Land Ice Measurements from Space (GLIMS) workshop, Boulder, Colorado, USA. Annals of Glaciology $\mathbf{5 0}$ (53), 53-69. doi: 10.3189/172756410790595804.
Ramsankaran RAAJ, Pandit A and Azam MF (2018) Spatially distributed ice-thickness modelling for Chhota Shigri Glacier in western Himalayas, India. International Journal of Remote Sensing 39(10), 3320-3343. doi: 10.1080/01431161.2018.1441563.

RGI Consortium (2020) Randolph Glacier Inventory - A Dataset of Global Glacier Outlines: Version 6.0: Technical Report, Global Land Ice Measurements from Space, Colorado, USA. Digital Media. doi: 10.7265/ N5-RGI-60.

Satylkanov R (2018) Ablation of ice and snow of Kara-Batkak Glacier and its impact on river flow. Journal of Climate Change 4(2), 1-14. doi: 10.3233/ jcc-180009.

Schaefli B, Manso P, Fischer M, Huss M and Farinotti D (2019) The role of glacier retreat for Swiss hydropower production. Renewable Energy 132, 615-627. doi: 10.1016/J.RENENE.2018.07.104

Shahgedanova M and others (2020) Emptying water towers? Impacts of future climate and glacier change on river discharge in the Northern Tien Shan, Central Asia. Water 12(3), 627. doi: 10.3390/w12030627.

Shean DE and 5 others (2020) A systematic, regional assessment of High Mountain Asia glacier mass balance. Frontiers of Earth Science 7, 363. doi: 10.3389/feart.2019.00363.

Solomina O, Barry R and Bodnya M (2004) The retreat of Tien Shan glaciers (Kyrgyzstan) since the little ice age estimated from aerial photographs, lichenometric and historical data. Geografiska Annaler: Series A, Physical Geography 86(2), 205-215. doi: 10.1111/j.0435-3676.2004.00225.x.

Sommer C, Malz P, Seehaus CT, Zemp M and Braun HM (2020) Rapid glacier retreat and downwasting throughout the European Alps in the early 21st century. Nature Communications 11, 3209. doi: 10.1038/ s41467-020-16818-0.

Sorg A, Bolch T, Stoffel M, Solomina O and Beniston M (2012) Climate change impacts on glaciers and runoff in Tien Shan (Central Asia). Nature Climate Change 2(10), 725-731. doi: 10.1038/nclimate1592.

Unger-Shayesteh K and others (2013) What do we know about past changes in the water cycle of Central Asian headwaters? A review. Global and Planetary Change 110, 4-25. doi: 10.1016/j.gloplacha.2013.02.004.

Ushnurtsev S (1991) Mass balance fluctuations of the Sary-Tor glacier in inner Tien Shan and its reconstruction for the period 1930-1988. Data of Glaciological Studies 71, 70-79 [in Russian].

Wang P and 5 others (2014) Ice thickness, volume and subglacial topography of Urumqi Glacier No. 1, Tianshan mountains, central Asia, by ground penetrating radar survey. Journal of Earth System Science 123(3), 581591. doi: 10.1007/s12040-014-0421-4.

Wang S and Zhou L (2017) Glacial lake outburst flood disasters and integrated risk management in China. International Journal of Disaster Risk Science $\mathbf{8}$ (4), 493-497. doi: 10.1007/s13753-017-0152-7.

WGMS (2019) Fluctuations of Glaciers Database. World Glacier Monitoring Service, Zurich, Switzerland. doi: 10.5904/wgms-fog-2019-12.

Zekollari H, Huybrechts P, Fürst JJ, Rybak O and Eisen O (2013) Calibration of a higher-order 3-D ice-flow model of the Morteratsch glacier complex, Engadin, Switzerland. Annals of Glaciology 54(63), 343-351. doi: 10.3189/2013AoG63A434.

Zemp $M$ and 14 others (2019) Global glacier mass changes and their contributions to sea-level rise from 1961 to 2016. Nature 1. doi: 10.1038/ s41586-019-1071-0.

Zhen W, Shiyin L, Shiqiang Z and Honglang X (2013) Internal structure and trend of glacier change assessed by geophysical investigations. Environmental Earth Sciences 68(6), 1513-1525. doi: 10.1007/s12665-012-1845-2. 